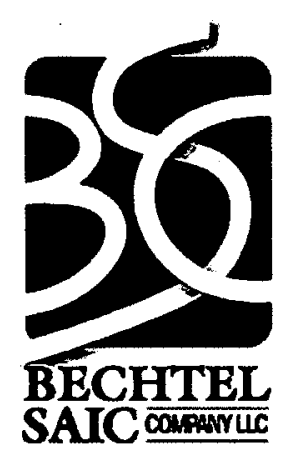

DOC.20060915.0004

QA: QA

TWP-MGR-GE-000006 REV 01

September 2006

\title{
Technical Work Plan for: \\ Construction Effects Monitoring
}

Prepared for:

U.S. Department of Energy

Office of Civilian Radioactive Waste Management

Office of Repository Development

1551 Hillshire Drive

Las Vegas, Nevada 89134-6321

Prepared by:

Bechtel SAIC Company, LLC

1180 Town Center Drive

Las Vegas, Nevada 89144

Under Contract Number

DE-AC28-01RW12101 


\section{DISCLAIMER}

This report was prepared as an account of work sponsored by an agency of the United States Government. Neither the United States Government nor any agency thereof, nor any of their employees, nor any of their contractors, subcontractors or their employees, makes any warranty, express or implied, or assumes any legal liability or responsibility for the accuracy, completeness, or any third party's use or the results of such use of any information, apparatus, product, or process disclosed, or represents that its use would not infringe privately owned rights. Reference herein to any specific commercial product, process, or service by trade name, trademark, manufacturer, or otherwise, does not necessarily constitute or imply its endorsement, recommendation, or favoring by the United States Government or any agency thereof or its contractors or subcontractors. The views and opinions of authors expressed herein do not necessarily state or reflect those of the United States Government or any agency thereof. 
Technical Work Plan for:

Construction Effects Monitoring

TWP-MGR-GE-000006 REV 01

September 2006 
Bechtel SAIC Company, LLC

Techuical Work Plan for:

Construction Fffects Monitoring

TWP-MGR-GE-000006 REV 01

September 2006

Prepared by:
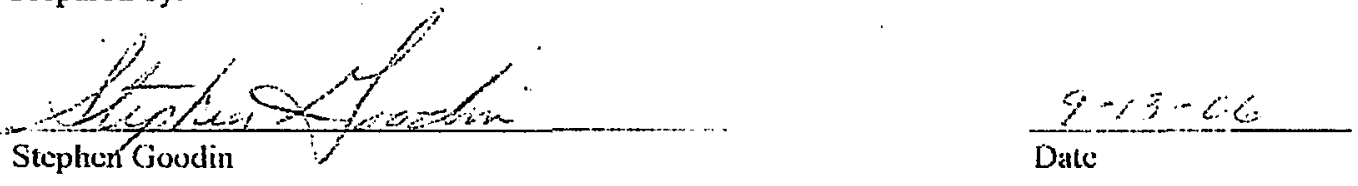

Performance Confirmation Staft

Datc

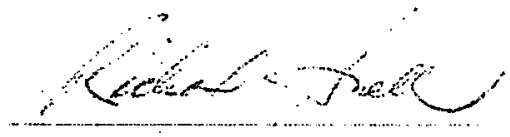

Richard Sncll

$7,3-06=$

Performance Confirnation Staff

Concurrence by:

(N/A)

Kenneth Skipper

USGS TPO

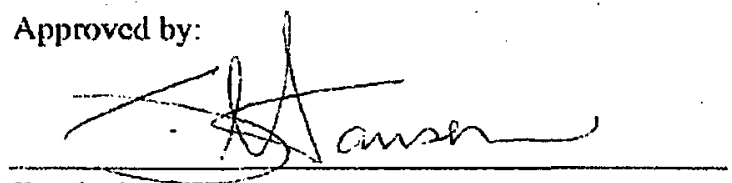

Frank Ilanscin

Performance Confirmation Department I.ead

$\frac{9-14-20002}{\text { Date }}$

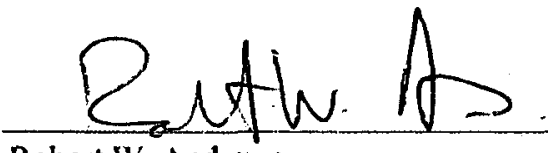

Robert W. Andrews

$9 / 14 / 06$

Datc

P'crformance Contirmation Manager (acting)

Datc 
INTENTIONALLY LEFT BLANK 


\section{CHANGE HISTORY}

$\begin{array}{cccl}\begin{array}{c}\text { Revision } \\ \text { Number }\end{array} & \begin{array}{l}\text { ICN } \\ \text { Number }\end{array} & \begin{array}{l}\text { Date of } \\ \text { Change }\end{array} & \begin{array}{l}\text { Description of Change } \\ 00\end{array} \\ & 00 & 05 / 31 / 2006 & \begin{array}{l}\text { Initial Issue - This is the initial issue of the } \\ \text { Performance Confirmation TWP for Construction } \\ \text { Effects Monitoring. A portion of the scope of this } \\ \text { Plan was initiated during site characterization and is } \\ \text { continued under the auspices of the Performance } \\ \text { Confirmation Program. }\end{array} \\ 01 & 00 & 09 / 14 / 2006 & \begin{array}{l}\text { Revision to address DOE comments. } \\ 0\end{array}\end{array}$


INTENTIONALLY LEFT BLANK 


\section{CONTENTS}

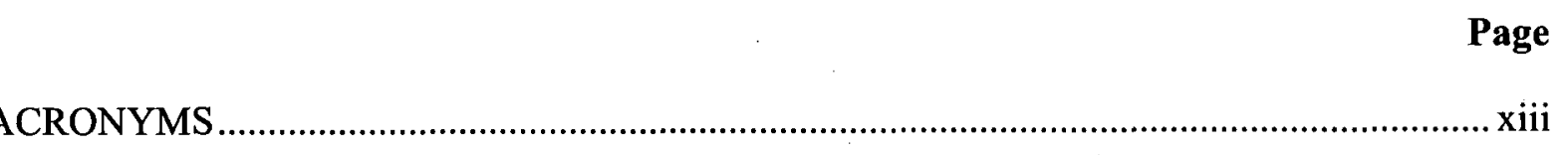

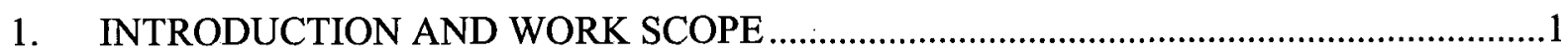

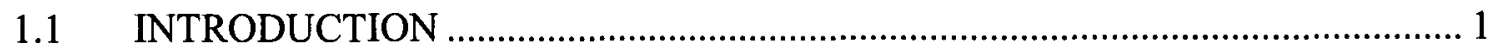

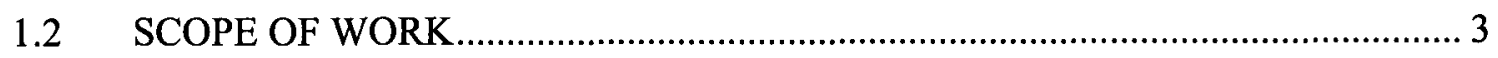

1.2.1 Overall Test Objectives..................................................................... 3

1.2 .2 Test Data/Work Product ................................................................... 8

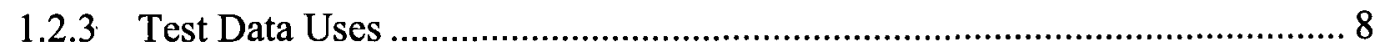

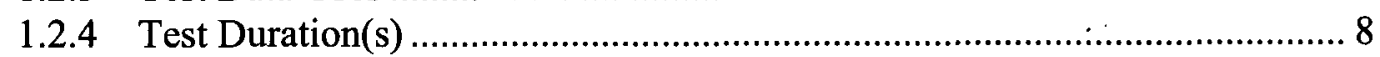

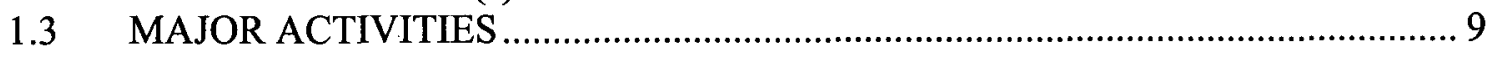

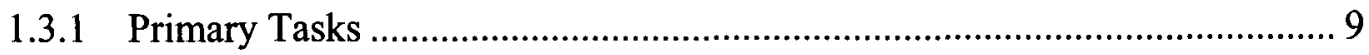

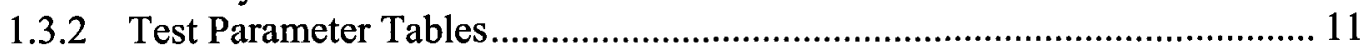

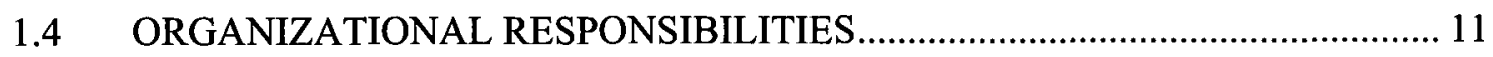

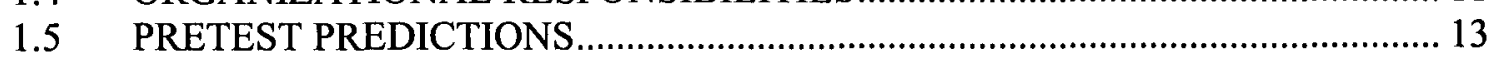

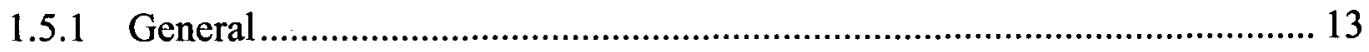

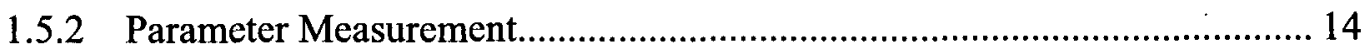

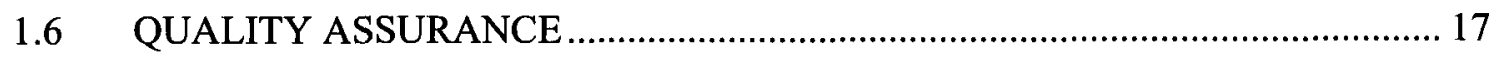

2. SCIENTIFIC APPROACH/TECHNICAL METHODS .............................................19

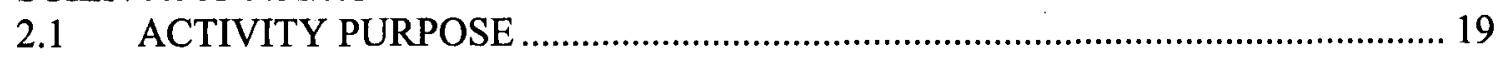

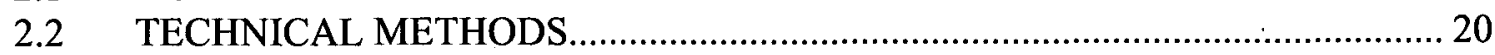

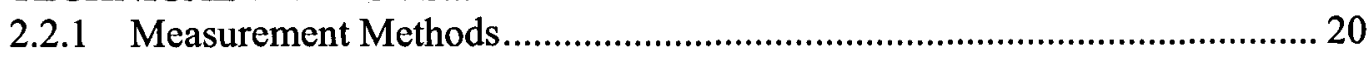

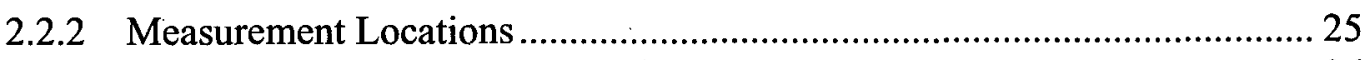

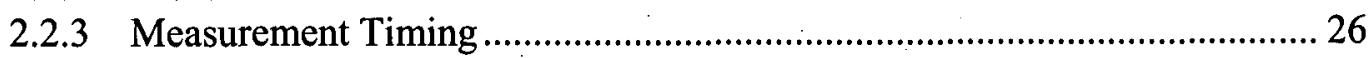

2.2.4 Test Implementation and Work Control Documents ............................... 27

2.3 DATA ACQUISITION, ANALYSIS, AND REPORTING OF RESULTS .......... 27

2.3.1 Data Acquisition .............................................................................. 27

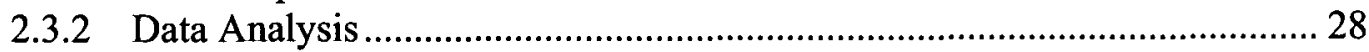

2.3.3 Data Submittal and Reporting........................................................ 30

2.4 PROVISIONS FOR UNEXPECTED RESULTS, CONDITIONS, AND OUT-OF-RANGE EVENTS ...................................................................... 30

2.4.1 General Provisions ........................................................................... 30

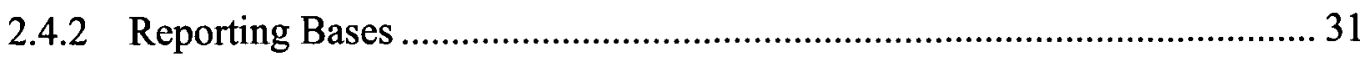

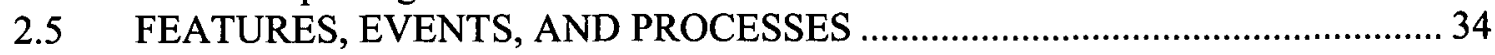

3. INDUSTRY STANDARDS, FEDERAL REGULATIONS, DOE ORDERS, and

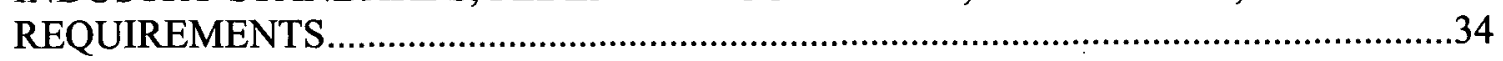

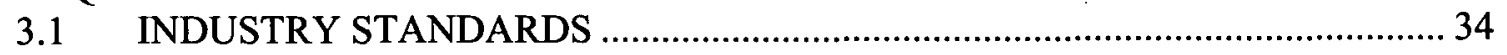

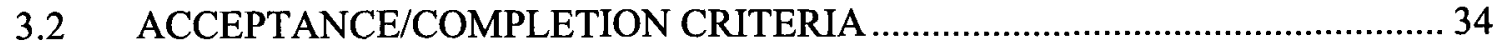

3.3 SOURCES OF ERROR OR UNCERTAINTY ….......................................... 34

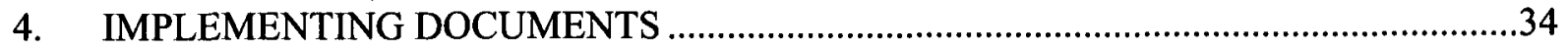


5. FIELD AND LABORATORY SYSTEMS AND EQUIPMENT ……................................35

$5.1 \quad$ MAJOR SYSTEMS AND EQUIPMENT ……….............................................. 35

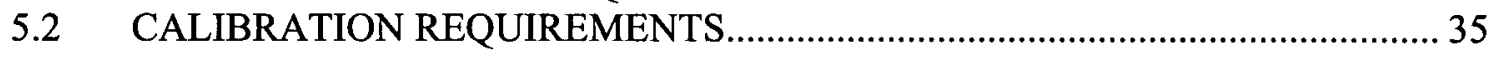

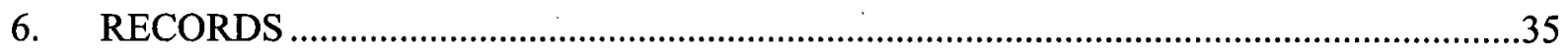

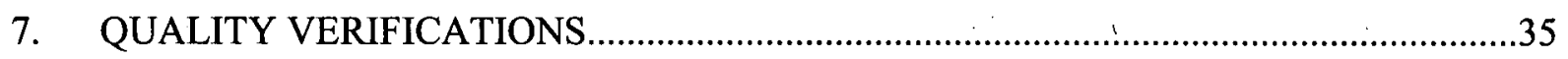

8. PREREQUISITES, SPECIAL CONTROLS, ENVIRONMENTAL CONDITIONS,

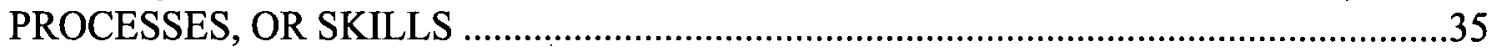

8.1 QARD REQUIREMENTS ……………………........................................ 35

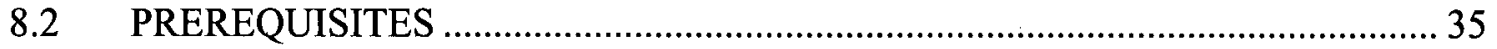

8.3 CONTROL OF ELECTRONIC MANAGEMENT OF INFORMATION............... 36

8.4 ENVIRONMENTAL CONTROLS .................................................................... 36

8.5 SPECIAL TRAINING/PERSONNEL QUALIFICATIONS ………....................... 36

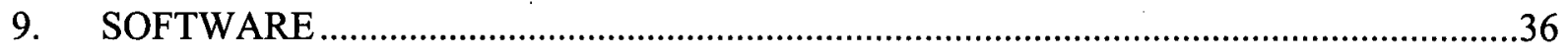

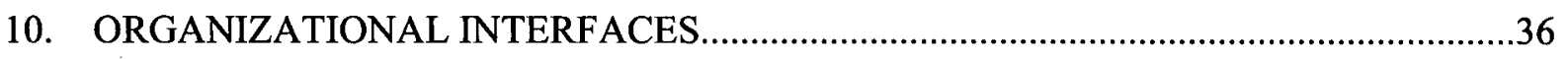

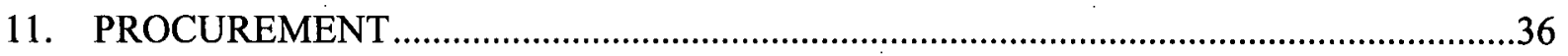

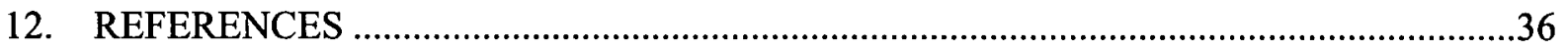

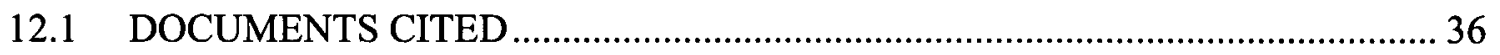

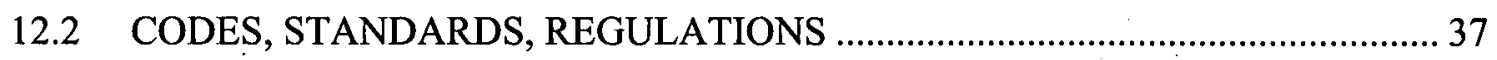

12.3 DATA, LISTED BY DATA TRACKING NUMBER ………………………......... 37

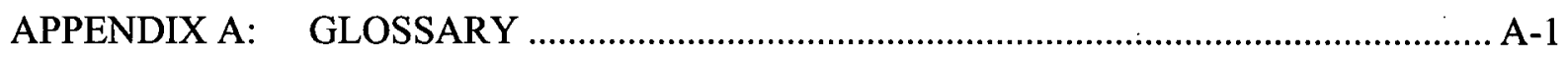

APPENDIX B: APPLICABLE PROCEDURES ……........................................................... 


\section{FIGURES}

Page

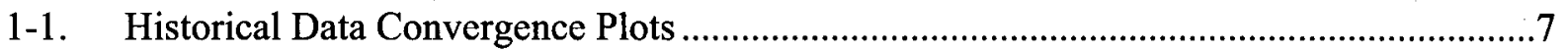

1-2. Logical Progression of Construction Effects Monitoring Testing and Evaluation............10

1-3. Typical Plots Showing Stable and Unstable Convergence Trends ................................18

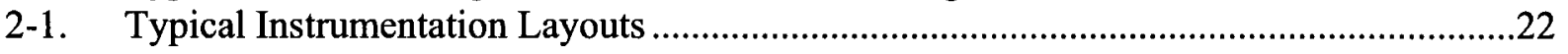

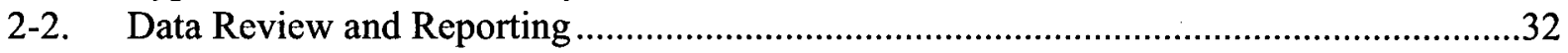


INTENTIONALLY LEFT BLANK 


\section{TABLES}

Page

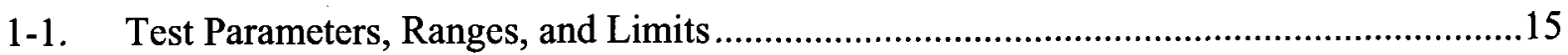

1-2. Supplemental Test Parameters .............................................................................16

2-1. Total Active Construction Monitoring Stations (MPBX and Convergence)...................26 


\section{INTENTIONALLY LEFT BLANK}




\section{ACRONYMS}

CEM

DOE

ECRB

ESF

FWP

LA

MPBX

NRC

PI

QARD

SITP

SPBX

TBM

TCO

TDMS

TWP

USGS

YMP
Construction Effects Monitoring

U.S. Department of Energy

Enhanced Characterization of the Repository Block Exploratory Studies Facility

Field Work Package

license application

multi-point borehole extensometer

U.S. Nuclear Regulatory Commission

Principal Investigator

Quality Assurance Requirements and Description

scientific investigation test plan

single-point borehole extensometer

tunnel boring machine

Test Coordination Office

Technical Data Management System

technical work plan

U.S. Geological Survey

Yucca Mountain Project 
INTENTIONALLY LEFT BLANK 


\section{INTRODUCTION AND WORK SCOPE}

\subsection{INTRODUCTION}

This document is the technical work plan (TWP) for performing the Construction Effects Monitoring (CEM) activity, which is one of 20 testing and monitoring activities included in Performance Confirmation Plan (BSC 2004 [DIRS 172452]). Collectively, the 20 activities make up the Performance Confirmation Program described in the plan. Each of the other 19 activities will have a separate TWP. This plan, though titled Construction Effects Monitoring, in accordance with the Performance Confirmation Plan, also includes testing that may be performed in addition to monitoring, if required. Performance confirmation is required by regulation 10 CFR Part 63 [DIRS 173273], and was started during site characterization (consistent with the regulation) and will continue until permanent closure of the repository (10 CFR 63.131(b) [DIRS 173273]). This CEM activity has two primary goals: (1) to collect, analyze, and report on repository rock properties data for the purpose of confirming geotechnical and design parameters used in repository design, and (2) to provide information intended to confirm that the ability to retrieve waste from the repository has been preserved. It will be necessary for information from this CEM activity to be evaluated in combination with that obtained from other Performance Confirmation Program activities to achieve these goals. These relationships with other Performance Confirmation Program activities (e.g., drift inspection, subsurface mapping, and seismicity monitoring) will be discussed in later sections of this TWP.

In response to the regulatory requirements discussed below, this TWP defines testing and monitoring scope, parameter selection, and test and monitoring methods. It also includes information such as test data expected ranges, condition limits, evaluation criteria, and reporting processes. If measurements or observations found during the testing and monitoring activity are outside of the expected conditions, appropriate evaluations and possible reporting to the U.S. Department of Energy (DOE) and the U.S. Nuclear Regulatory Commission (NRC) will be performed in accordance with AP-REG-009, Reportable Geologic Condition.

Construction Effects Monitoring is part of a Performance Confirmation Program for which the purpose and objectives are defined in 10 CFR 63.102(m) [DIRS 173273]. Regulatory requirements for the Performance Confirmation Program are specified in 10 CFR 63 Subpart F [DIRS 173273]. Regulatory performance objectives for the overall repository are stated in 10 CFR 63 Subpart E [DIRS 173273]. Guidance for the Performance Confirmation Program is also provided in Yucca Mountain Review Plan, Final Report (NRC 2003 [DIRS 163274]). A description of the Performance Confirmation Program is required in the Safety Analysis Report as part of the license application (LA) (10 CFR 63.21(c)(17) [DIRS 173273]).

Test and monitoring activities in this TWP address 10 CFR 63.131 and 63.132 [DIRS 173273], which require that the Performance Confirmation Program provide data, observations, and geotechnical information that indicate, where practicable, whether actual subsurface conditions encountered and changes in these conditions during construction and waste emplacement operations are within the limits assumed in the technical analyses supporting the LA.

This TWP plans for activities to comply with 10 CFR 63.131(a)(1), (b), (c) [DIRS 173273] and 10 CFR 63.131(d)(1), (d)(2), (d)(3) [DIRS 173273]. This does not apply to 10 CFR 63.131(a)(2) 
[DIRS 173273] in that the design analyses that use the parameters confirmed in this activity are not directly related to barrier performance but to the response and interaction of the natural system with the designed subsurface excavated openings. This work includes in situ testing and monitoring activities and baseline data from those activities that were performed during site characterization and may continue until permanent closure. Activities in this TWP provide baseline information regarding the response of the natural system to the design system and monitoring of the baseline data for changes that could affect performance of the designed subsurface openings during the preclosure period. Confirmation of preclosure engineered system performance is not directly related to total system performance assessment, although monitoring data collected may be used outside of this TWP for evaluation of postclosure subsurface opening design and also for comparison with data collected under thermally accelerated conditions. The postclosure predicted condition of ground support design is that the emplacement drifts in lithophysal rock will collapse due to seismic induced stresses, and because of this, postclosure opening stability does not require confirmation. Confirmation of preclosure ground support is, however, needed since 10 CFR 63.132 [DIRS173273] requires confirmation of the geotechnical and design parameters used in supporting design analyses. The confirmation of these input parameters will be used to show that ground support design is adequate to maintain the stability of the preclosure subsurface opening and ensure, in part, retrievability. Activities included in this plan do not adversely affect the performance objectives of the planned engineered elements.

This TWP specifically complies with 10 CFR 63.132(a) [DIRS173273], which states:

During repository construction and operation, a continuing program of surveillance, measurement, testing, and geologic mapping must be conducted to ensure that geotechnical and design parameters are confirmed and to ensure that appropriate action is taken to inform the Commission of design changes needed to accommodate actual field conditions encountered.

Several other performance confirmation activities also evaluate subsurface characteristics, as described in the following sections of this TWP. For waste emplacement drifts, the scope of this activity is limited to the preemplacement time period. Other Performance Confirmation Program activities and TWPs will provide data for waste emplacement drifts to address subsurface conditions and changes in those conditions during waste emplacement and thereafter. For nonemplacement subsurface areas this activity includes the entire time period until closure.

This TWP activity data/information (as well as from the other 19 performance confirmation activities) will be evaluated in the context of overall repository performance. An original set of performance confirmation activities was proposed as important to measure repository performance, during the course of a multi-attribute decision analysis process described in an earlier version of Performance Confirmation Plan (Snell 2003 [DIRS 166219]). Modifications to the original activity set (including this activity) were made during technical and management reviews (documented in revisions to the plan). Although the activities and the systems that they monitor, as described in this document, may not be directly related to waste isolation and barrier performance, the need still exists to confirm the geotechnical design input parameters through ongoing monitoring and testing activities. Confirmation of these parameters along with observation of opening stability through scheduled visual surveillance will also be used for confirmation of the ability to retrieve waste during the preclosure period. This will be performed 
by evaluation of the geotechnical input parameters and predictions from supporting engineering analyses for excavated opening ground support design. These parameters or predictions will be compared to historical and future data that will be used to measure the effectiveness of the design system. Other testing programs (e.g., those conducted for engineering and construction) may provide additional information or test data, which will be available to the Performance Confirmation Program for comparison purposes. This additional information could be useful and will be incorporated into the Performance Confirmation Program data, as required.

Historical data from convergence has been collected under an existing scientific investigation test plan (SITP) entitled Test Plan for: Construction Monitoring Equipment Installation and Data Collection (BSC 2003 [DIRS 170210]). This SITP will continue to use the data collected from convergence monitoring, strain gages, and other instrumentation for use by design engineering for understanding the effects that seismic events may have on existing ground support or other needed data input. This TWP uses a subset of the data that is currently collected under the existing SITP for evaluation of historical data and to evaluate ongoing preclosure engineered system performance of the Exploratory Studies Facility (ESF) tunnels.

This TWP is written specific to Construction Effects Monitoring, in accordance with LP-2.29Q-BSC, Planning for Science Activities, with additional information to address Performance Confirmation Plan (BSC 2004 [DIRS 172452]) and to address the requirements in Quality Assurance Requirements and Description (QARD) (DOE 2004 [DIRS 171539]). This TWP contains sufficient information to describe the purpose, objectives, and scope of the associated activities, test methodology, equipment and instrumentation planned for use, data management, calibration requirements, and acceptance criteria for the results.

\subsection{SCOPE OF WORK}

\subsubsection{Overall Test Objectives}

\subsubsection{Testing and Monitoring Requirements}

The scope of work for this TWP is to perform the testing and monitoring required to obtain data and information to confirm geotechnical input parameters listed in Tables 1-1 and 1-2. This TWP also includes surveillance activities that will be additionally used to confirm the stability of the subsurface openings and thus retreivability. Although this TWP is used to plan performance confirmation activities, it does not plan for model or analysis development. The overall schedules and timing of the testing and monitoring will be in accordance with Section 2.2.3. Additional scheduling details will be developed as part of a Field Work Package (FWP) or separate project control baselines.

Requirements for construction effects testing and monitoring for that activity were outlined in Performance Confirmation Plan (BSC 2004 [DIRS 172452]), which states:

Candidate parameters that may be measured include: drift convergence, tunnel stability, and engineered ground support systems. Geotechnical rock properties may be evaluated at selected locations. This activity supports evaluation of the performance of the Upper and Lower Natural Barriers in the vicinity of the repository drifts and mains by confirming the mechanical properties. This long- 
term field observation program provides a direct measurement of in situ conditions that will likely vary spatially.

Drift convergence has been predicted using the analytical techniques identified in Ground | Control Emplacement Drifts for LA (BSC 2004 [DIRS 170292]) and Ground Control for Non-Emplacement Drifts for LA (BSC 2004 [DIRS 168178]). The predictions depend on geomechanical rock parameters (such as rock mass modulus, Poisson's Ratio, in situ stress). Measured drift convergence and changes in measured drift convergence (trends which may be indicative of opening stability) will be compared to predicted values. In cases where there are significant differences between predicted and measured values of convergence and/or convergence trends, the Performance Confirmation Manager, in concert with recommendations from the Principal Investigator (PI), may determine that further geotechnical data are needed. The relationships between convergence and supporting geotechnical parameter data are further discussed in Section 1.2.1.2.

Other candidate parameters assigned to the Performance Confirmation Plan are planned to be performed under a future TWP, which may include ground support system monitoring and other rock properties (in addition to rock mass modulus, Poisson's ratio, and in situ stress) testing that may be selected to supplement the data for confirmation of rock classification. Monitoring the response of the natural system from the effect of excavated openings in thermally accelerated emplacement drifts and geologic mapping of tunnels will be planned also under future thermally accelerated drift and geologic mapping TWPs. Shaft behavior will be monitored under the repository development program and is not included in the scope of this TWP. Data from that program will be available, however, to the Performance Confirmation Program for comparison purposes or supplementation, if needed.

Advances in technology can be expected to occur over the next several decades. A successful program is flexible and includes a process to reevaluate, reexamine, and modify performance confirmation activities as the state of understanding changes. New tests may be needed or may become possible with new technology, and tests that are not providing useful information could be discontinued.

\subsubsection{Testing And Monitoring Objectives}

The objective of the testing and monitoring described in this TWP is to make observations and collect data through monitoring and testing activities that will be used to meet the regulatory requirement discussed in Section 1.1. Data collected from previous construction monitoring activities and continuing under this TWP include rock displacement (i.e., convergence of excavated openings).

Section 1.2.1.1 notes that convergence in the underground openings has been predicted using the analytical techniques in ground control design calculations (BSC 2004 [DIRS 170292]; BSC 2004 [DIRS 168178]). In the event that measured convergence values are significantly different from calculated values, it will be necessary to conduct further evaluations to understand the cause of the differences. These evaluations may include additional testing of rock properties. 
To select the relevant rock properties, which might be tested, a review of the calculation method has been performed that identifies those having the most influence on convergence values (BSC 2004 [DIRS 170292], Table 3-4). This review shows that predictive calculations created five categories of rock properties to address the substantial variations for rock quality in the repository footprint. Category 1 corresponds to the weakest or lowest quality rock properties. Higher quality rock was assigned higher category numbers with Category 5 having the strongest/best quality properties.

In order to take a conservative approach to ground support design, the design calculations were based on Category 1 rock property parameter values. This category assignment takes into account the lithophysal porosity of the rock ranging from $25 \%$ to $30 \%$. Poisson's Ratio was taken to be constant or all categories (0.22). Friction angle was also taken to be a constant for all categories (45 degrees). Cohesion (MPa) has a significant influence but is in direct proportion to the unconfined compressive strength $(\mathrm{MPa})$. The primary properties influencing the predictive calculations listed in Table 3-4 are, therefore, the rock modulus, unconfined compressive strength, and Poisson's ratio input values for Category 1 rock. An additional influencing factor may be the in situ horizontal-to-vertical stress ratio. A lower horizontal stress component $\left(\mathrm{K}_{o}=0.3\right)$ apparently results in relatively larger vertical rock convergence. This stress ratio may be determined by performance of in situ stress testing at selected locations underground, typically in areas that are showing higher values of opening convergence.

In the event of significant difference between measured and predicted values of convergence, the PI, in conjunction with the Performance Confirmation department and, with subject matter experts, will identify additional testing and monitoring that should be performed. This potential additional work could also depend on other performance confirmation observations and on reviews of the analytical basis for the predictions, as discussed above.

Additional data will be collected for performance confirmation under this TWP, as necessary, following convergence monitoring data collection. This data will be collected through supplemental testing and may include rock mass modulus, in situ stress, and Poisson's Ratio. Values of rock properties from data may be used to confirm parameter input values used in design predictions and to help identify which, if any, input parameters may be outside of the expected range of values used in design analyses. Unconfined compressive strength data obtained from core sampling is not representative of lithophysal rock and is not planned to be collected for that reason. If required, unconfined compressive strength values can be derived from slot testing. Visual observations will provide direct evidence of the predicted condition of the underground openings remaining stable during the preclosure period.

Portions of this activity began during site characterization. Presently, data are collected as a subset of the initial suite of monitoring stations located in the ESF and in the Enhanced Characterization of the Repository Block (ECRB) facility. The data collected show that the response of the rock surrounding the excavated openings in the ESF has responded as modeled by calculations performed in Ground Control for Emplacement Drifts for LA (BSC 2004 [DIRS 170292]) and Ground Control for Non-Emplacement Drifts for LA (BSC 2004 [DIRS 168178]). The plotted curves of the data collected at stations in the ESF and ECRB tunnels (DTN: SN0405F3312393.015) indicate that the majority of the convergence has occurred in the excavated openings during the first 300 days following excavation, which was 
predicted from the calculations. The historical data confirm that the rock in the ESF openings is responding, as predicted, and that convergence of the opening is approaching a value of zero as time increases. Continued collection of convergence data in the ESF should show a continuation of near zero to no convergence occurring in the existing excavated openings. These stations will also provide useful data related to seismic event occurrences and the effect, or lack thereof, on opening convergence. The predicted condition for preclosure seismic events is that the effect on opening convergence will be minimal (BSC 2004 [DIRS 168178]).

Figure 1-1 shows plots of ESF (upper) and ECRB (lower) multi-point borehole extensometer (MPBX) station data showing a typical decreasing rate of convergence over time. The plots show convergence based on various anchor point depths. The upper curve (yellow) on each represents plotted data from the deepest anchor point (approximately $7.6 \mathrm{~m}$ ). Rock type is nonlithophysal in ESF and lithophysal in the ECRB. Note the small amount of maximum deformation that was actually measured (approximately $0.5 \mathrm{~mm}$ and $0.3 \mathrm{~mm}$ ) indicating that a majority of the convergence occurred prior to instrumentation of the site. These plots show a decreasing rate of convergence approaching zero, which is the expected result and corresponds to the typical characteristic plot in Figure 1-3. 

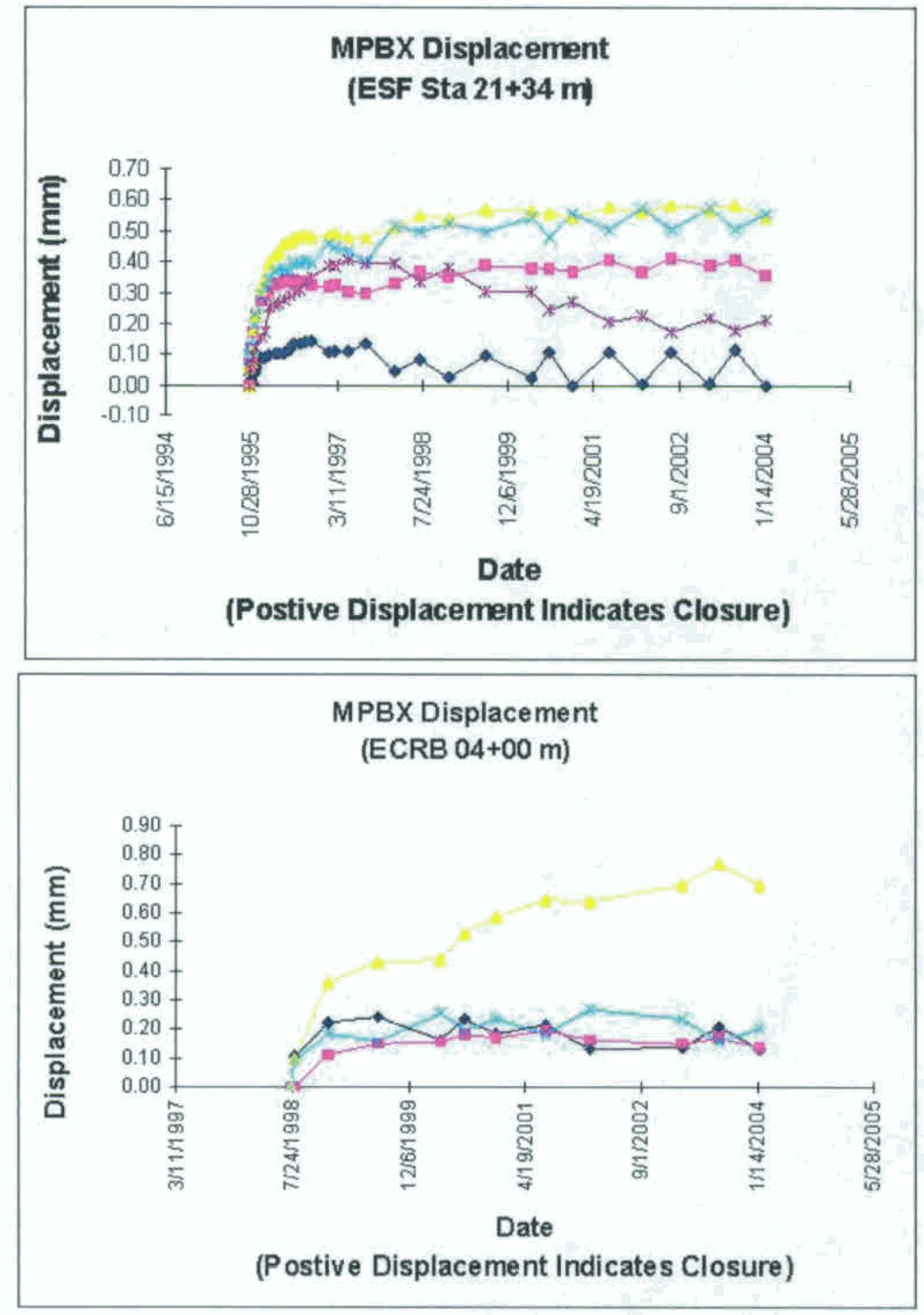

Figure 1-1. Historical Data Convergence Plots 


\subsubsection{Test Data/Work Product}

The confirmatory testing pursued in this performance confirmation TWP will be compared to the input parameters used to predict drift stability. The predictive models were based on site characterization tests for physical and mechanical rock properties and empirical rock classifications made regarding rock quality and strength.

Information to be gathered or calculated includes: (1) tunnel deformation measurements (used to compare with calculated values), (2) tunnel degradation (visual observation of significant drift rockfall occurrence), (3) geotechnical rock properties (e.g., calculated rock mass modulus, in situ stress, and Poisson's ratio determinations) that will be compared with values used in engineering analyses inputs (BSC 2004 [DIRS 170292]; BSC 2004 [DIRS 168178]) and are listed in Table 1-1. Data collected will be submitted to the Technical Data Management System (TDMS) following review and necessary reduction.

\subsection{3' Test Data Uses}

The data and information gathered under this performance confirmation activity will be used to support the following:

- Confirmation of the geotechnical input parameters (i.e., convergence, rock mass modulus, Poisson's ratio; and in situ stress) obtained from analyses that support underground opening design.

- Confirmation, in part, of preservation of the ability to retrieve waste until permanent closure.

- Observation of the condition of the underground openings at regular intervals and following significant seismic events, should they occur during the preclosure period. These observations will be assessed in concert with other performance confirmation activities such as Seismicity Monitoring and Subsurface Mapping to determine opening stability.

- Comparisons with data/information from related performance confirmation activities such as Drift Inspection and Thermally Accelerated Drift thermal-mechanical monitoring.

\subsubsection{Test Duration(s)}

Construction effects monitoring located in emplacement drifts will cease before waste emplacement, since the scope of this TWP only covers monitoring in ambient temperature conditions. It is expected that long-term monitoring in access ramps and mains may continue to be conducted through the preclosure period for confirmation of opening stability and associated retrievability or until it has been determined by the Performance Confirmation department that it is no longer needed for confirmation. 


\subsection{MAJOR ACTIVITIES}

This test plan includes a level of detail for instrument installation, testing and monitoring, data collection and analysis, and reporting that can be used in conjunction with FWP documents and technical procedures for test implementation. Additional types of test procedures, construction monitoring instrumentation, or different data collection techniques may be incorporated into this plan, as needed. Primary tasks and the sources of testing/monitoring details are listed below.

\subsubsection{Primary Tasks}

The tasks generally covered by this TWP include, but are not limited to:

- Confirm test parameters and requirements (Table 1-1)

- Define test parameter expected range and condition limit (Table 1-1)

- Develop a general list of instrumentation (Section 2.2)

- Provide necessary test installation details (Section 2.2)

- Identify any special procurement requirements for instruments and test materials (Section 11)

- Specification of calibration requirements (LP-12.1Q-BSC, Control of Measuring and Test Equipment, Section 2.2; IT-PRO-0011, Software Management)

- Preparations for installation of instrumentation, as required (Section 2.2 and technical procedures)

- Installation of cabling and wire runs (see FWP-ESF-96-001, Field Test Data Collection Systems, for installation details)

- Installation and setup of data acquisition systems (see Section 2.3 and FWP for installation and setup details)

- Data downloads, raw data reduction, analysis, evaluations (Sections 2.3 and 2.4; IT-PRO-0009, Control of the Electronic Management of Information; LP-12.1Q-BSC; IT-PRO-0011)

- Data submittal to the records system and TDMS (Sections 2.3 and 2.4, AP-17.1Q, Records Management).

- Reporting of data evaluations per AP-REG-009.

Figure 1-2 shows the logic flow for the planned testing activity and the sequence by which testing, data collection, and evaluation of data will be performed. 


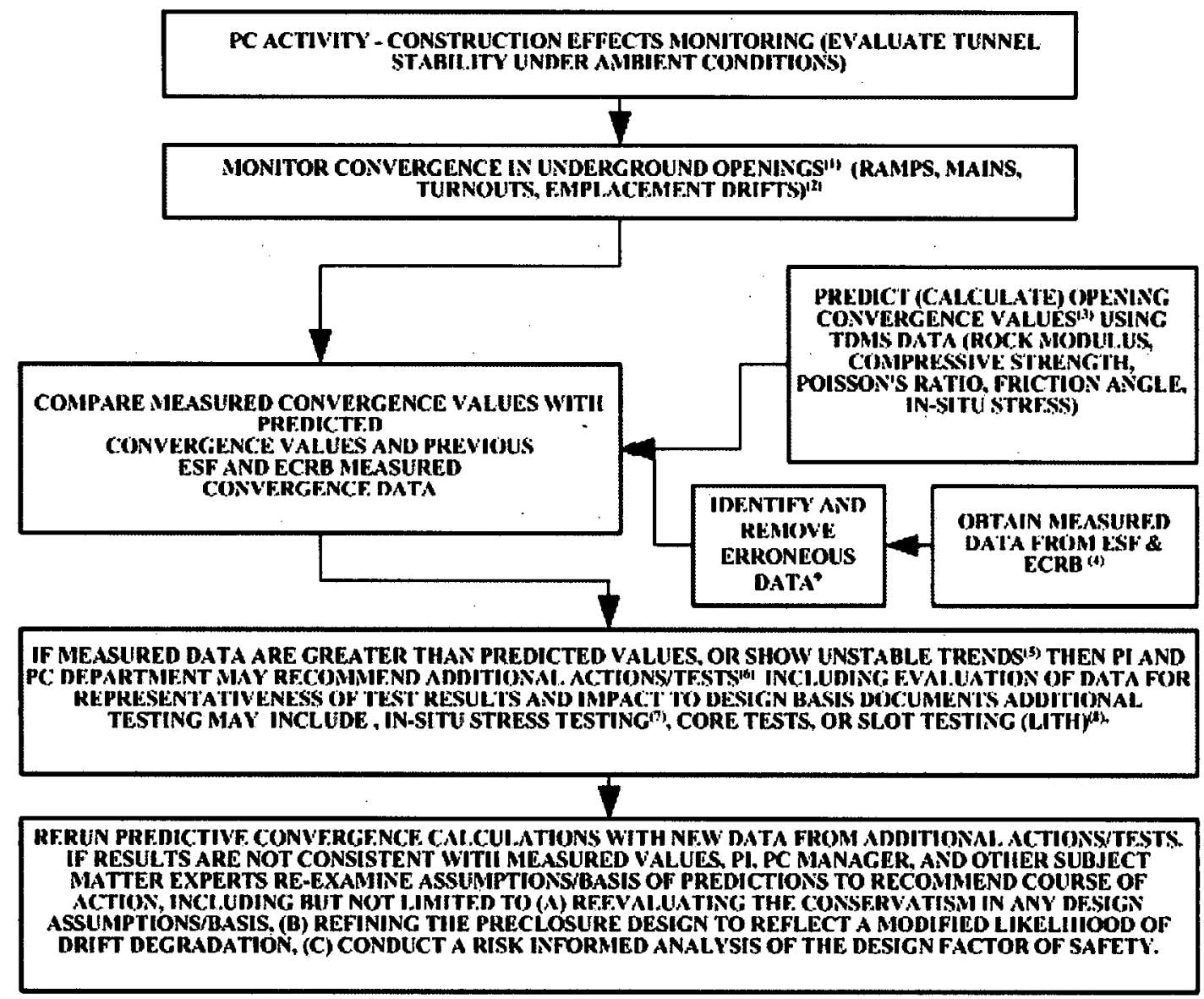

NOTES:

1. Convergence monitoring will be performed using tape extensometer and/or MPBX methods. Convergence of the underground openings is a function of local rock properties and variation of measured convergence from predicted (calculated) convergence suggests that the rock properties used in the calculations are not appropriate and/or that the predictive (calculation) model needs to be modified.

2. For emplacement drifts, monitoring will be performed prior to the installation of permanent ground support (a full coverage stainless sheet liner). The liner is planned to be installed three to six months after tunnel boring machine (TBM) excavation. Ground support in ramps, mains, and turnouts will still provide direct access to the rock face (except for locally shotcreted areas in turnouts) for the entire preclosure period.

3. See calculation Ground Control for Emplacement Drifts for LA (BSC 2004 [DIRS 170292]).

4. ESF and ECRB data files are available in the TDMS.

5. See Figure 1-3 for definition/description of stable/unstable trend conditions.

6. See Figure 2-2 for definition of the procedure to be used for unexpected conditions or events.

7. See Table 1-1 for a listing and brief description of optional tests.

8. Slot testing (not listed in Table 1-1 because it is a time-consuming test compared to the limited time window of three to six months for emplacement drifts) could, however, be added as a test activity if deemed necessary by the PI, PC Department, and/or Subject Matter Experts.

9. See Section 2.3.1.

Figure 1-2. Logical Progression of Construction Effects Monitoring Testing and Evaluation 


\subsubsection{Test Parameter Tables}

The monitoring activities included in this plan will be performed to obtain values for comparison with the convergence parameter values listed in Table 1-1. Exceedance of these values from their expected ranges will trigger further evaluation of the rock mass, including testing for supplemental input parameters listed in Table 1-2. Table 1-1 shows several sets of CEM1 parameter expected ranges that have been categorized according to size of opening and rock type (lithophysal vs. nonlithophysal). able includes a series of convergence monitoring parameters (CEM1 and CEM2) that encompass the various underground opening sizes in lithophysal and nonlithophysal rock. Table 1-1 also contains a parameter for significant rockfall occurrences. This parameter (CEM3) has an expected range of no rockfall to minor surficial rock spalling (e.g., air slack). The condition limit set for this parameter was based on analysis predictions for the preclosure period. Exceeding expected range values of convergence may require additional field testing for determination of in situ parameters CEM4, CEM5, CEM6, and CEM7 listed in Table 1-2.

Convergence values given in Table 1-1 represent total predicted convergence for the preclosure period based on rock type and opening span. However, measurements taken in the underground openings are of the deformation (movement) of the roof only and do not measure the invert movement. Thus, direct measured values of roof deformation in the field will not be representative of the total convergence values given in Table 1-1. For this reason, roof deformation values will need to be multiplied by two to obtain drift convergence values. The measured values have been predicted to be $25 \%$ of total convergence, thus measured values will be multiplied by 2 to convert from roof deformation to convergence and an additional factor of 4 to compare with the total convergence value given in Table 1-1 (BSC 2004 [DIRS 168178], p. 29).

\subsection{ORGANIZATIONAL RESPONSIBILITIES}

This performance confirmation activity is field-based and requires integration and support from several Yucca Mountain Project (YMP) entities. These specific interfaces will be defined in the implementing FWP, providing specific details on field interactions, data handoffs, and coordination aspects of the fieldwork. Entities currently (preconstruction) having responsibilities associated with this field activity include the Performance Confirmation department, Engineering Subsurface Design, Performance Assessment Modeling and Analysis departments (including Total System Performance Assessment), the Test Coordination Office (TCO), the PI, ESF Site Operations, and the Licensing and Analysis organization. Once a license to construct the repository is obtained, there will be responsibilities for Repository Construction and Repository Operations departments that will require revision to this test plan.

The Performance Confirmation department is responsible for ensuring that work is conducted in accordance with the regulatory requirements and other considerations delineated in the Performance Confirmation Program. This department assumes overall project management for the program and the central interface between the performance assessment modelers, the DOE, and the TCO (implementing) organizations. This department is responsible for preparing and approving this test plan, ensuring communication and agreement between the modelers and the field testers, arranging for the technical review of the field results as they become available, and 
updating testing and monitoring strategies, as necessary. The department serves as the conduit for notification from the PI, if field results are found outside expected ranges or condition limits, and is responsible for notifying the DOE through the Licensing and Analysis organization. The Licensing and Analysis organization has responsibilities related to reporting, through the DOE, to the NRC, for any out of condition limit situations, in accordance with the process described in Section 2.4.2. At present, the procedure used to accomplish this is AP-REG-009.

The TCO is responsible for overall field management, coordination, and monitoring of field test activities. A function of coordination is needed to integrate field support requirements, quality requirements, environmental safety and health requirements, and hazard analysis and controls into the FWPs. The TCO also assists in the permitting, estimating, and integrated scheduling. FWPs and associated test work authorization documents are currently developed in accordance with PA-PRO-0308, Testing Work Implementation and Control. This test coordination function works closely with the Performance Confirmation department to ensure the successful planning and implementation of the program. The TCO provides for the sample management function, field oversight of the work activities, and the field scientific/technical staff for the installation and maintenance of test equipment and the collection and initial evaluation of the data associated with this workscope. This department is responsible for submittal of the data to the TDMS.

Subsurface Engineering will provide further resources and technical expertise to assess the impacts of conditions that have exceeded limits. Engineering will work closely with the Performance Confirmation department in evaluation of data from test and monitoring activities. Requests from the Performance Confirmation department will be made to engineering, as required, for determination of impacts to design analyses or other technical information.

The ESF Site Operations comprise multiple departments (e.g., Operations, Maintenance, Construction, Field Engineering, and Field Industrial Hygiene staff), which provide site infrastructure/access, logistics, craft labor, and emergency response to support testing. ESF Site Operations support specific to testing activities are requested, planned, scheduled, and conducted via OP-PRO-9101, Work Control Process, consistent with baseline budget and resource levels managed within a TCO work package. Support required for this activity is currently limited to tunnel accesses, man-lift and train support for convergence readings and maintenance. ESF Site Operations also provides for the ESF Site Project Field Engineering department, which may provide support for the tunnel walkdowns, as described in Section 2.3.2.2.

Repository Construction and Repository Operations departments will have responsibilities in the future related to all Site-required interfaces, including access and craft support for test activities.

U.S. Geological Survey (USGS) personnel will provide mapping of the subsurface under a separate TWP. Should conditions warrant, mapping will be used in concert with the data collected by work activities described by this TWP. USGS personnel may also be called upon for identification or interpretation of geologic conditions, as needed by the Performance Confirmation department.

At present, integration, data review, and evaluation are performed within the Performance Confirmation department and applicable Performance Assessment and TCO scientific departments. In the future, a performance confirmation integration group would be developed, 
consistent with Performance Confirmation Plan (BSC 2004 [DIRS 172452]), to review performance confirmation data and evaluate the overall status of the program. In addition, the integration group would be designed to ensure continuity and integration with other testing and monitoring programs. The group would determine whether the incremental results within the Performance Confirmation Program are interrelated, technically adequate, properly documented, and properly evaluated. This evaluation would ensure that preclosure engineered system performance is assessed in the context of all relevant performance confirmation information.

\subsection{PRETEST PREDICTIONS}

\subsubsection{General}

This performance confirmation activity provides geomechanical data and observations with regard to construction effects, as defined in this plan, at ambient temperatures. Table 1-1 includes expected ranges of parameters used in design analyses supporting LA and based on data collection from geomechanical testing and convergence monitoring stations in the ESF and the ECRB. Data collection at selected convergence monitoring stations will continue on a regular basis. The data have been submitted to the TDMS along with plotted curves of displacement vs. time. The most recent data set submitted (DTN: SN0405F3312393.015) contains all the data collected since 1999 and is qualified.

Pretest predictions or expectations for parameters are identified as expected range values in Table 1-1. These values for convergence were obtained from engineering ground support analyses that provide the design basis for ground support in the subsurface excavations (BSC 2004 [DIRS 170292]; BSC 2004 [DIRS 168178]). These analyses categorized lithophysal and nonlithophysal rock into five categories, category one rock being the poorest and category five rock representing the highest rock quality. The convergence numbers in Table 1-1 provide Category 1 rock values for convergence at various locations in the planned repository, including the access main tunnels, emplacement drifts, turnout drifts, and intersection points between the turnout drifts and the main access tunnels. Category 1 rock was used for all expected range values since this represents the worst case of expected rock quality and is what design engineers have used for design of the ground support systems.

At the present time, analyses have not been performed to establish condition limits for convergence in these areas. The condition-limit values would be derived by decreasing the factor of safety in the models until just prior to failure (essentially at a factor of safety of 1 ). These values will be provided in a future pretest prediction report. Currently, no new excavation is planned for several years, and thus having these limit values is not critical at this time. Existing excavated openings have generally reached steady state with little or no convergence, and thus it is not critical to have condition limits at this time. This TWP will be revised in the future to incorporate the calculated condition limit values that are derived once the pretest prediction report is completed.

The expected range values essentially represent the upper value of the expected convergence, and thus, the range is from a value of zero to that shown in Table 1-1. If measurements exceed the expected range under this TWP, then an evaluation will be initiated to determine the probable cause of the out of bound condition and whether operational condition or safety is impacted. 


\subsubsection{Parameter Measurement}

\subsubsection{Basis for Expected Range and Condition Limit}

Total convergence expected ranges given for CEM1 and CEM2 in Table 1-1 are based on the values calculated for Category 1 rock types and their corresponding subsurface opening sizes performed in the ground control analyses that support LA subsurface design (BSC 2004 [DIRS 170292]; BSC 2004 [DIRS 168178]). Because ground support design was based on Category 1 rock, only Category 1 rock expected ranges have been established for use in this confirmation activity.

Visual monitoring of excavated opening stability (CEM3) has an expected value of no occurrences (null set) of significant rockfall (greater than $1.3 \mathrm{~m}^{3}$ per event) in the emplacement drifts during the preclosure period. This has its basis in the ground control analyses for subsurface design of the emplacement drifts (BSC 2004 [DIRS 170292], p. 104). The condition limits for this parameter have been conservatively taken to be anything greater than the expected range values.

Expected range values for mechanical rock properties of the nonlithophysal and lithophysal rock types are provided in Table 1-2 as CEM4 through CEM7. Parameter expected ranges/values are listed in the ground control analyses (BSC 2004 [DIRS 170292]; BSC 2004 [DIRS 168178]). These values will be compared with data collected typically during the evaluation process, which will be initiated in the case that convergence expected ranges are exceeded. During this evaluation process, the PI's (and the Performance Confirmation department's) technical expertise and judgment will be used to determine if differences exist in measured values of CEM4 through CEM7 with those given in Table 1-2 that are indicative of an out of range condition, and if so, does the condition have a potential significant impact on the supporting design bases. This evaluation by the PI will be documented in the regular data report to be submitted to the NRC, as described in Section 2.4. Evaluation of any trends in the collected data will be performed on an ongoing basis. This will include plotting of convergence data showing the cumulative measured convergence vs. time.

Emplacement drift rock will only be directly accessible (i.e., prior to installation of permanent ground support) for a period of perhaps up to six months following TBM excavation. Convergence monitoring of the underground openings has therefore been selected as a surrogate method of determining rock mass modulus. Convergence expected ranges are also predicted in the ground control analyses and, therefore, included as a parameter in Table 1-1 for excavated intersections, main access, turnout, and emplacement tunnels. Condition limit values have not been determined at this time for opening convergence since a predictive calculation is needed to determine these values by means of a future analysis. Since no new excavations are planned for several years and all current excavations are showing stable conditions with little or no convergence, the need for the condition limit values is not required at this time. However, the development of the supporting calculation and revision to this TWP may be required prior to the start of new repository tunnel excavation. 
Table 1-1. Test Parameters, Ranges, and Limits

CONSTRUCTION EFFECTS MONITORING (224)

(Monitoring Tunnel Stability Under Ambient Pre-emplacement Conditions)

\begin{tabular}{|c|c|c|c|c|}
\hline \multicolumn{2}{|c|}{ PRIMARY TEST PARAMETERS } & $\begin{array}{c}\text { EXPECTED } \\
\text { RANGENALUE }\end{array}$ & $\begin{array}{c}\text { CONDITION } \\
\text { LIMIT }\end{array}$ & $\begin{array}{c}\text { COMMENTS ON PARAMETER SIGNIFICANCE, RATIONALE, } \\
\text { BASIS FOR EXPECTED RANGE }\end{array}$ \\
\hline$* \quad$ DESCRIPTION - PRIMARY PARAMETERS &
\end{tabular}

\begin{tabular}{|c|c|c|c|c|}
\hline CEMi & $\begin{array}{l}\text { Tunnel Convergence Monitoring } \\
\text { (MPBX Measurements) } \\
\text { (Ongoing and Construetion Phase) }\end{array}$ & & & \\
\hline CEM1a & $\begin{array}{l}\text { Tunnel Convergence - Ramps and Mains } \\
\text { (nanithophysal) } 7.6 \mathrm{~m} \text { Diarneter Operingj }\end{array}$ & 0 to $120 \mathrm{~mm}$ & TBD & $\begin{array}{l}\text { 1. Data collection will start us soon as feasiblo atter TBM excavation. 2. Exceedance of } \\
\text { expected range will require internal evaluation of condition and detemine requirements for } \\
\text { reporting externaly. Expected range values for convergence derived by multiplying predicted } \\
\text { roof deformation (BSC 2004a and BSC 2004b) by two. }\end{array}$ \\
\hline CEMID & $\begin{array}{l}\text { Tunnel Convergence - Mains (ithophysal) } \\
\text { (f.6m Diameter Opening) }\end{array}$ & $01056.0 \mathrm{~mm}$ & TBD & 1. See CEMia notes. \\
\hline CEMic & $\begin{array}{l}\text { Tunnel Convergence - TurnoulMain Intersection } \\
\text { (nonlithophysal) }\end{array}$ & 0 to $20.0 \mathrm{~mm}$ & TBD & 1. See CEM1a notes. \\
\hline CEMId & $\begin{array}{l}\text { Turnel Convergence - TumoulMain Intersection } \\
\text { (ithophysal) }\end{array}$ & 0 to $128 \mathrm{cmm}$ & TBO & 1. See CEMTa notes. \\
\hline CEMie & $\begin{array}{l}\text { Tunnel Convergence - Emplacement Drit } \\
\text { (nonilhophysa) (5.5m Dameter Opening) } \\
\text { (Temporary Ground Support for approximately } \\
\text { first three months) }\end{array}$ & O to $10.0 \mathrm{~mm}$ & TBD & 1. See CEMTa notes. \\
\hline CEMIf & $\begin{array}{l}\text { Tunnel Convergenoe - Empliscement Drit (ithophysai) } \\
\text { (5.5m Diameter Opeening) (Temporary Ground Support } \\
\text { for approximately first three months) }\end{array}$ & 0 to $55.0 \mathrm{~mm}$ & TBD & 1. See CEM ta notes. \\
\hline CEM/2 & $\begin{array}{l}\text { Turnel Mine - By Monitoring (using Rod } \\
\text { Extensometers) (Construction Phase) }\end{array}$ & & & \\
\hline CEM/2 & $\begin{array}{l}\text { Tunnei Convergence Monitoring (Rod Extensometers) } \\
\text { (Nenticat Component) }\end{array}$ & $\begin{array}{c}\text { See Values in CEM1 } \\
\text { for Opening Size, } \\
\text { and Rock Type }\end{array}$ & TBD & $\begin{array}{l}\text { 1. Exceedance of expected range wall requine internal evaluation of condition and will determine } \\
\text { requirements for reporting externally. }\end{array}$ \\
\hline \multicolumn{2}{|r|}{ EXCLUSIVELY EMPLACEMENT DRIFT MONITORING } & & & \\
\hline CEM 3 & $\begin{array}{l}\text { Significant Rock Fall Occurrence } \\
\text { (visual observations of tunnel profie) }\end{array}$ & $\begin{array}{l}\text { No Rock Fall } \\
\text { to Minor Spalting }\end{array}$ & $\begin{array}{l}\text { Rock Fall }>1.3 \mathrm{~m}^{3} \\
\text { in Volume }\end{array}$ & 1. Expected Range and Condition Limit see (DIRS 170292), pg 104. \\
\hline
\end{tabular}

1) Tunnel deformation measurement predictions are caloutated values.

2) Rock thermal properties data are not included since this activity addresses pre-emplacement construction effects 
Table 1-2. Supplemental Test Parameters

\begin{tabular}{|c|c|c|c|}
\hline \multicolumn{2}{|c|}{ PRIMARY TEST PARAMETERS } & $\begin{array}{r}\text { EXPECTED } \\
\text { RANGEVALUE }\end{array}$ & $\begin{array}{c}\text { COMMENTS ON PARAMETER SIGNIFICANCE, RATIONALE, } \\
\text { BASIS FOR EXPECTED RANGE }\end{array}$ \\
\hline$*$ & DESCRIPTION - PRIMARY PARAMETERS &
\end{tabular}

\begin{tabular}{|c|c|c|c|}
\hline \multicolumn{2}{|c|}{$\begin{array}{l}\text { SUPPLEMENTAL TEST PARAMETERS IN CASES WHERE } \\
\text { CONVERGENCE RANGES ARE EXCEEDED }\end{array}$} & & \\
\hline CEMA & Rock Mass Modulus (E) (nonithophysal) & $10.2 \cdot 26.1 \mathrm{GPa}$ & 1. Expected from [DIRS 168178], Table 4-2. \\
\hline CEMS & Rock Mass Modulus (E) (ithophysal)' & $1.9 \cdot 19.7 \mathrm{GPa}$ & 1. Expected Range from [DIRS 168178]. Tabie 4-1. \\
\hline CEMG & In Situ Stress & $\begin{array}{c}\sigma_{1}=\text { Calculated } \\
\text { based on } \mathrm{xd} \\
\sigma_{2}=\sigma_{1} \times 0.617 \\
\sigma_{3}=\sigma_{1} \times 0.361\end{array}$ & $\begin{array}{l}\text { 1. In Stu Stress Measurements performed as required when convergence expected ranges are excoeded. } \\
\text { 2. } \sigma_{2} \text { and } \sigma_{3} \text { factors from [DIRS } 168178 \text { ] } \mathrm{pg} 29 \text {. }\end{array}$ \\
\hline CEM7a & Poisson's Ratio (nonlithophysal) & 0.19 & 1. Current Data Range from [DIRS 168178 ], Tabie 4-2. \\
\hline CEM7b & Poisson's Ratio (Itthophysai) & 0.22 & 1. Current Data Range from [DIRS 168178], Table 4-1. \\
\hline
\end{tabular}


Evaluation of trends indicating possible instability of the openings (especially where convergence is measured at large span openings) will be performed using Figure 1-3. Figure 1-3 does not address all possible modes and trends of failure (especially for nonlithophysal rock) but can be used for determining stability of an opening in certain rock types (i.e., some lithophysal rocks). If any trend is noted indicating that an unstable condition exists, after required corrections for error have been accounted for and based on the PI's technical expertise in conjunction with Performance Confirmation Program manager approval, reporting will be performed in accordance with Section 2.4. This evaluation is performed primarily to confirm the ability to retrieve waste from the repository drifts but also has importance to operational and personnel safety; thus, any evaluation of data that indicates an unstable condition will be reported the same way as that for exceeding a condition limit.

\subsubsection{Relevance to Requirements}

Primary confirmation activity of this TWP is to ensure that geotechnical design parameters related to the design of the subsurface openings are confirmed. This confirmation is also relevant to the ability to retrieve waste during the preclosure time period. 10 CFR Part 63 [DIRS 173273] requirements state that conditions must be monitored, including key geotechnical parameters, to identify any significant changes to conditions, as assumed in the LA. A significant condition is one that has an adverse impact on "the conditions assumed in the license application and that may affect compliance with the performance objectives" (10 CFR 63.102(m) [DIRS 173273]). This type of condition will require NRC notification as discussed in Section 2.4.2. Additionally, waste retrieval is reliant on the stability of the subsurface tunnels for removal of waste packages. Thus, as opening stability is confirmed, retrievability is also confirmed in part, as related to this design system. The requirements related to the implementation of this TWP are given in Section 1.

\subsection{QUALITY ASSURANCE}

This activity is subject to the requirements of the QARD (DOE 2006 [DIRS 176927]) and will be updated accordingly as requirements change. This TWP for the construction effects testing and monitoring activity was prepared in accordance with LP-2.29Q-BSC. Requirements specific to performance confirmation, as identified in Performance Confirmation Plan (BSC 2004 [DIRS 172452]), are added to this TWP, as applicable. 


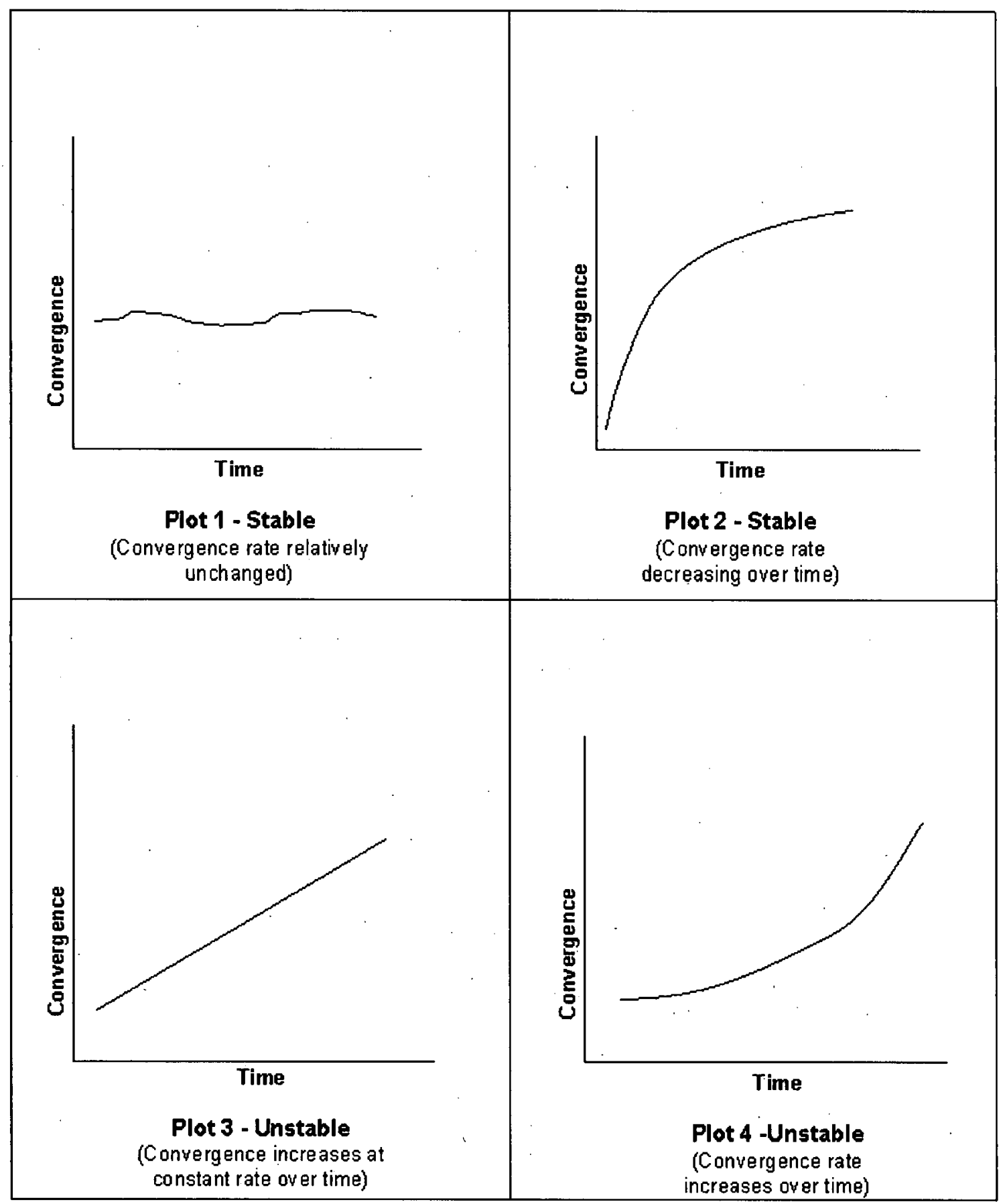

Figure 1-3. Typical Plots Showing Stable and Unstable Convergence Trends 


\section{SCIENTIFIC APPROACH/TECHNICAL METHODS}

\subsection{ACTIVITY PURPOSE}

The design analyses assess ground stability, predicting that openings remain stable throughout the operational preclosure period. Stability will be increased further when permanent ground support is erected within months of initial excavation of emplacement drift openings. The supporting engineering ground control analysis (BSC 2004 [DIRS 170292]) was conducted for open emplacement drifts and shows only minor rockfall for preclosure seismic loading in the lowest quality rock. Therefore, the expectation from deformation measurements is confirmation of design performance of the underground excavated openings and their related ground support system.

The installed ground support system performance will be confirmed by ensuring that the bounding conditions used in design are within the expected ranges for their corresponding rock properties. The design analyses (BSC 2004 [DIRS 170292]; BSC 2004 [DIRS 168178]) have used the lowest quality rock (Category 1) in design of the ground support system, and thus the ground support system is designed to perform adequately for all higher categories (higher quality) of rock (Categories 2 through 5). This TWP confirms the input parameters (rock mass modulus, in situ stress, Poisson's Ratio) used for Category 1 and thus assumes that if these input parameters do not exceed their expected range values that the ground support system will be adequate for all rock types. It is important to note that it is not the intent of this confirmation activity to address all potential anomalous rock conditions (key blocks, etc.) that may exist during excavation, since it is impossible to predict or locate all localized conditions that will potentially be encountered during excavation of miles of repository drifts.

If excessive deformation is observed, it could indicate that the rock properties input to the supporting analysis did not adequately capture the material response of the medium. Thus, excessive deformation measurements would first be reconciled with the five rock mass categories utilized in the calculations. The rock mass categories ( 1 is low quality and 5 is high quality) are primarily functions of lithophysal porosity. All expected ranges for convergence are based on a Category 1 rock type for lithophysal and nonlithophysal rock. Therefore, when excessive deformation is observed, other performance confirmation activities and results of those activities, such as mapping, will be used to evaluate lithophysal content and other rock unit structural features for the monitored area. Any monitored areas that exceed the ranges and limits established for drift convergence are thus expected to be Category 1 rock. If, however, a higher rock categorization (i.e., Categories 2 through 4) is found to be outside of expected range, evaluation and reporting of the condition will still apply. The Performance Confirmation Manager will initiate an evaluation of the condition if the convergence range is exceeded. The PI may request of the Performance Confirmation Manager further testing of the rock to obtain data on rock modulus, in situ stress, and Poisson's ratio values. A back analysis will then be performed on the area in question using these values of convergence, stress, and Poisson's ratio to determine the rock mass modulus. If the calculated values of rock mass modulus or the measured values of convergence are outside of the ranges and/or limits specified in Table 1-1, then internal and external reporting will be performed as required and specified in Section 2.4. 
In addition to convergence and rock mass modulus parameters, visual drift inspection for underground openings (CEM 3, Table 1-1) will provide added confirmation of structural stability. The assessment of unstable events will be performed by physical walkdown and visual inspection of existing ESF tunnels and future excavated repository tunnels on a regular basis for indications of rockfall induced by key block failures in nonlithophysal rock and by persistent fallout caused by highly fractured or altered rock zones in the lithophysal rock units. These observations will be used to confirm the ground support analyses that have predicted no significant rockfall (i.e., rockfall quantities within the expected ranges) will occur in these units during the preclosure period. Additionally, walkdowns will be performed following seismic events that are considered significant, as determined by estimated peak ground velocity at the repository location. The peak ground velocity trigger value for initiating a walkdown will be provided by a future Seismic Monitoring TWP or as directed by the Performance Confirmation Manager. Any localized areas of instability will require external reporting to the NRC through the DOE and possible instrumentation to monitor for safety and operational concerns.

Several other test activities are planned under future TWPs that will be used in confirmation of the rock mass modulus and other parameters supporting subsurface design analyses. One of these will be the TWP for the thermally accelerated drift near-field environment. In addition to other measurements, this TWP is intended to measure the convergence in the thermally accelerated drift and confirm the effect that thermally induced stresses have on excavated openings. This near field plan will also monitor for any structural instabilities in the emplacement drifts following waste emplacement using remote video equipment and/or acoustic monitoring techniques. A mapping TWP will additionally be used in conjunction with this TWP for establishment of rock categories and other structural and lithologic characteristics of the rock in the areas monitored, as required.

\subsection{TECHNICAL METHODS}

\subsubsection{Measurement Methods}

The equipment currently used for obtaining measurements described in this plan includes convergence pins, MPBXs, or single-point borehole extensometers (SPBXs). Future equipment employed in displacement measurements will most likely use a system of reflective survey points and an electronic laser type distance measuring device that will replace the current convergence tape equipment. MPBX and SPBX equipment installed in the future will collect data continuously and provide a much more accurate time measurement of displacement occurrences than the current system. The system is valuable in collection of data immediately following seismic events and for conditions that could lead to a possible unsafe condition in the subsurface. This approach will increase the reliability of deformational measurements planned for drift inspection use in emplacement drifts after waste emplacement. This plan will be revised, as needed, to incorporate new test equipment and test and monitoring methods as they are improved through development of new technology. Configuration management control of test equipment installation, although not covered in this revision, may be addressed in revisions of this plan for test equipment installation in future repository excavations. 
The types of information to be collected include:

- Tunnel convergence from survey points installed in emplacement drifts, mains, intersections, and ramps along the vertical and horizontal surfaces of underground openings

- Rock displacement data from rod extensometers installed in tunnel springline, invert, and back or surrounding the tunnel opening (in the case of mine-by tests)

- Tunnel degradation (visual observations for structural instability)

- In situ rock stress measurements, as necessary

- Rock core tests for Poisson's ratio, as necessary.

\subsubsection{Tunnel Deformation (Tape Extensometers)}

Tunnel deformation monitoring, including deformation measurements performed with MPBX or SPBX gages, and convergence pin measurements will provide data that can be used to determine whether the tunnel or drifts are in a stable or unstable structural condition. Tape extensometers will be installed as required to provide a larger range of convergence measurement. Although data collected from tape extensometers are not as accurate as that collected from MPBX gages, this equipment will be used, as needed, for secondary MPBX data confirmation. Tape extensometer stations will be located adjacent to MPBX and SPBX gage stations.

The convergence monitoring system currently consists of pins placed into the rock formation (or attached to steel sets, if required). The distance between the installed pins is measured using a tape extensometer connected between opposing pins. The diagram in Figure 2-1 shows a typical convergence pin array installation. Measurements are presently made with a tape extensometer between the invert pin and the crown pin, although future measurements are planned to measure displacement using laser measurement or other means that provides input to a continuous monitoring data collection system. Because the tunnel temperature has seasonal variability, the temperature will be recorded and thermal-based corrections will be made to the data, as necessary. The tape will be checked for damage by a performance check that is accomplished using a steel frame of known length and at a specified temperature. The length of the steel frame is measured using the tape.

\section{$\underline{\text { Steel Frame }}$}

Range: 34.6025 in. (or metric equivalent)

Tolerance: \pm 0.001 in. (or metric equivalent)

The dial gage used for reading the extensometer tape is calibrated to manufacturers' specifications. 


\section{Tape Extensometer Gage Manufacturers' Specifications}

\section{Performance}

Range: 0 to 2.0 inches ( $50.8 \mathrm{~mm}$ )

Accuracy: \pm 0.001 inches

Resolution: $1 / 1000$ th of an inch (or metric equivalent)

Electrical

Excitation: N/A

Output: Inches or Metric

Environmental

Temperature: $15^{\circ} \mathrm{F}$ to $+160^{\circ} \mathrm{F}\left(-10\right.$ to $\left.+60^{\circ} \mathrm{C}\right)$

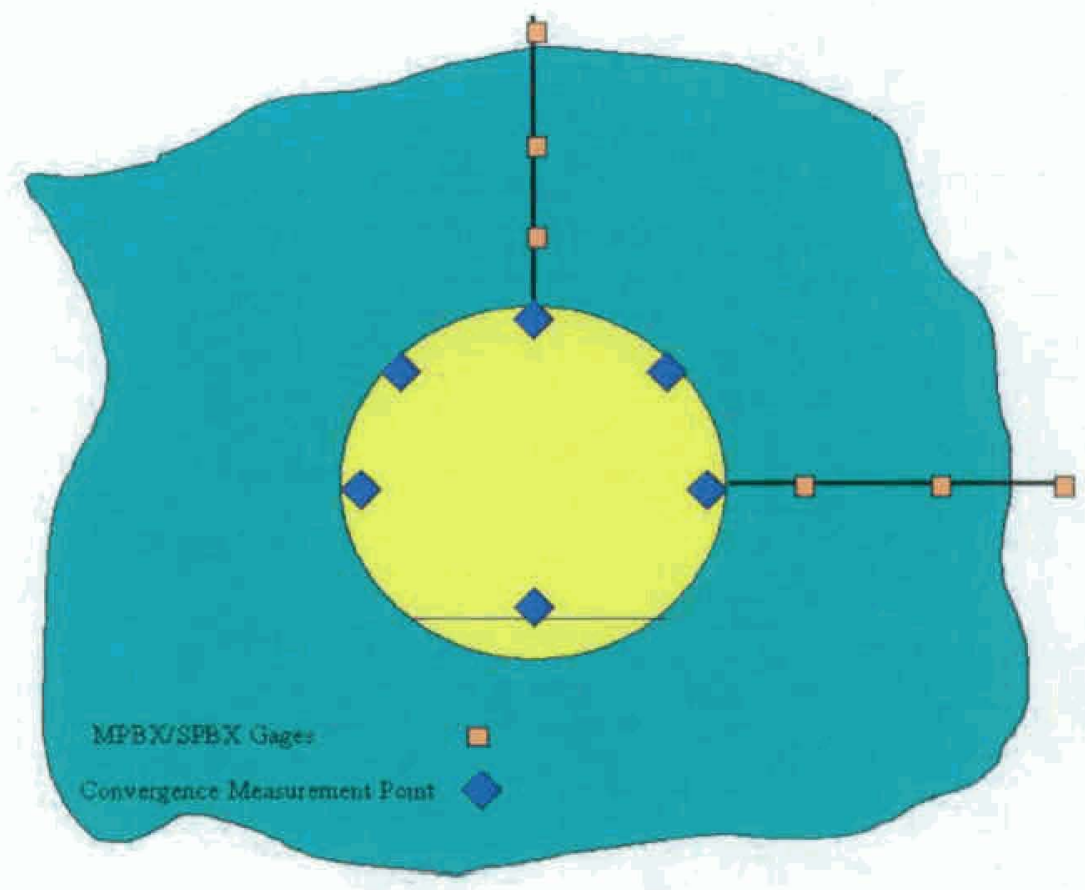

Figure 2-1. Typical Instrumentation Layouts 


\subsubsection{Tunnel Deformation (Rod Extensometers)}

Borehole extensometers (MPBX and SPBX) are instruments used to measure displacement of rock at various depths in a borehole. The MPBX gages have multiple anchors in each borehole that provide an accurate deformation measurement relative to various distances from the excavated surface into the rock. All stations will require at least one anchor point located at a distance of one tunnel diameter or greater from the opening. A fix anchor is assumed at this or greater depth from the excavated crown. Data collected from this point in a vertical anchor will be used in comparisons with Table 1-1. Other shallower anchor point data will be used to confirm deeper anchors. Typical MPBX and SPBX configurations are shown in Figure 2-1. The field test staff will ensure that extensometers are suitably anchored into the rock to prevent slippage.

Mine-by extensometers are planned to be installed to measure initial excavation deformation during excavation of the test observation drift and main access tunnels. The test observation drift will be monitored using rod extensometers installed from the invert of the Main Drift. The observation drift will pass underneath the Main Drift during early stages of excavation. Rod extensometer anchors will extend to just above the designed observation drift crown with additional anchors located at varying distances from the drift crown, as determined by the PI. These instrument gages will measure the vertical deformation of the excavated opening. The PI will determine anchor point placement. Two other possible locations are planned from the ECRB drift and repository main access tunnel intersections. The extensometers will be installed in drill holes collared in the invert of the ECRB drift and extend to near the crown of the main access tunnels.

\section{$\underline{\text { MPBX and SPBX Specifications }}$}

\section{Performance}

Range: 0 to $1.0 "$ ( 0 to $25.4 \mathrm{~mm}$ )

Accuracy: \pm 0.001 inches

Resolution: $0.025 \% \mathrm{FS}$

\section{Electrical}

Excitation: $\leq 35$ VDC

Output: N/A

\section{Environmental}

Temperature: $-85^{\circ} \mathrm{F}$ to $+257^{\circ} \mathrm{F}\left(-65^{\circ} \mathrm{C}\right.$ to $\left.161^{\circ} \mathrm{C}\right)$ 


\subsubsection{Emplacement Drift Degradation and Ground Support Monitoring (Visual Observations)}

The visual observation and recording of structural instability occurrences will be monitored in the current ESF North Ramp, Main, South Ramp, and ECRB tunnels. The ongoing observation of this measurement and future excavation measurements will confirm the predictions of the design analysis (BSC 2004 [DIRS 170292]) that no significant rockfall should occur during the preclosure period. This measurement will confirm that the interaction between the design and natural system is performing as assumed in the LA. Recording of results and reporting will be performed in accordance with the applicable procedures.

Observation for structural instability occurrences using regular scheduled inspections will be performed in the emplacement drifts prior to the installation of permanent ground support, since the installation of permanent ground support will severely inhibit observations from being conducted. However, this TWP addresses only the observation of existing and future emplacement drifts at ambient temperature conditions. Observation of emplacement drifts will be conducted on a regular basis (perhaps daily) from the drift entry to the area of new construction.

Any rockfalls showing evidence of the following conditions will be noted in a monitoring report, and will be further documented using digital photographic methods:

- Rockfall or raveling observed from the tunnel back or ribs onto the tunnel invert in the lithophysal or nonlithophysal rock units including repeated falls from the same location

- Key block fallout of material observed from the tunnel back or ribs onto the tunnel invert (or entrapped above welded wire fabric) in the nonlithophysal rock units (or in the case of emplacement drifts, prior to permanent ground support installation).

A determination of the extent of these observations (i.e., the entire drift or selected sections within the drift), as well as consideration of potential changes to the methods being used to perform this activity, will be made by the Performance Confirmation organization based on the observed conditions.

Obvious damage/degradation will be noted in a report as described in Section 2.4.2. The PI, or PI designee, and the Performance Confirmation organization will review data from all such rockfall locations. At a minimum, each location should be scheduled for a short-term reinspection and reevaluation.

The invert will be monitored for rock material that has fallen from the back or ribs of the drifts. Visual observation will be used to assess the condition of the tunnel invert, ribs, and crown. Where determined necessary, volume estimates will be made as determined by the PI.

\subsubsection{In Situ Rock Stress Measurements}

In situ stress measurements will be made using borehole deformation gage, hydraulic fracturing techniques, or other methods. The first technique uses a borehole deformation gage inserted into a small diameter hole drilled into the rock at the required depth for testing. This gage is then 
overcored by a larger-diameter cored hole, and data from the deformational response is used in determination of the in situ stress state. The PI will determine borehole orientation and locations for these tests, with approval by the Performance Confirmation Manager. Rock core from this testing may also be used for determination of Poisson's ratio and unconfined compressive strength values determined through laboratory testing of core samples.

Another method that may be used for determination of in situ stress is the hydraulic fracturing method. This method is performed inside a borehole at the specified depth. A section of the borehole is isolated using inflatable packers and the isolated section is then pressurized with water until a fracture is formed and propagated through the rock. The pressure (shut-in) required to sustain the open fracture is then recorded and used for determination of the in situ stress magnitudes. In situ testing is primarily supplemental and may be performed in instances where the expected range or condition limit values for tunnel convergence have been exceeded.

\subsubsection{Measurement Locations}

Continued convergence monitoring is planned for the present stations located along the North Ramp, Main Drift, South Ramp, and ECRB tunnel. Table 2-1 shows the current active stations in the ESF subsurface used for construction monitoring.

For future initial emplacement drift development, rock displacement monitoring instrumentation will be installed in at least two, and possibly three or more locations within the emplacement drifts. Rock displacement will also be monitored in the future access mains, turnout drifts, and the intersection of turnouts and emplacement drifts in Panel No. 1. At a minimum, two locations will be required to reflect conditions in both the nonlithophysal rock zones on the entry side of each drift and the lithophysal rock zones on the exhaust side of each drift. Intersections will provide a location of maximum span of the tunnel back that will be the most conservative location for monitoring tunnel convergence. Instrumentation will also require installation near the midpoint of some or all of the initial emplacement drifts in order to provide baseline (i.e., unheated) data for comparison with the data from the thermally accelerated drifts. Additional areas that may be monitored for retrievability include locations with geologic features such as faults, fractures, and raveling rock, as encountered during excavation. It may also be possible, based on early data evaluations, to determine that fewer locations within each drift are required and that every drift does not require instrumentation.

The measurement locations for mine-by monitoring may include the plan view intersections of | the Main Drift and the test observation drift and the intersection of the ECRB drift and mined access drifts for repository emplacement drifts. Exact locations will be determined following final design completion.

The PI will determine locations for supplemental testing for in situ stress measurements in each area where convergence ranges and or limits are exceeded. 
Table 2-1. Total Active Construction Monitoring Stations (MPBX and Convergence)

\begin{tabular}{|c|c|c|c|c|c|c|c|c|}
\hline$\#$ & $\begin{array}{c}\text { Station } \\
\text { Name }\end{array}$ & $\begin{array}{c}\text { Station } \\
\text { Location }\end{array}$ & \# & Station Name & $\begin{array}{c}\text { Station } \\
\text { Location }\end{array}$ & \# & Station Name & $\begin{array}{c}\text { Station } \\
\text { Location }\end{array}$ \\
\hline 1 & 5 & $00+05 \mathrm{~m}$ & 21 & 6306 & $63+06 \mathrm{~m}$ & 41 & ECRB 805 & E $08+05 \mathrm{~m}$ \\
\hline 2 & 9 & $00+09 \mathrm{~m}$ & 22 & TTF/AOD $00+41 \mathrm{~m}$ & TTF/AOD $00+41 \mathrm{~m}$ & 42 & ECRB 1617 & $\mathrm{E} 16+17 \mathrm{~m}$ \\
\hline 3 & UTCA $00+24$ & ALC. $100+24$ & 23 & TTF/AOD 01+31 & TTF/AOD 01+31 m & 43 & ECRB 1625 & $E 16+25 \mathrm{~m}$ \\
\hline 4 & Steel Set 114 & $01+96 \mathrm{~m}$ & 24 & 6795 & $67+95 \mathrm{~m}$ & 44 & Steel Set 291 & $05+42 \mathrm{~m}$ \\
\hline 5 & 413 & $04+13 \mathrm{~m}$ & 25 & NGDFA $00+80$ & NGDFA $00+80 \mathrm{~m}$ & 45 & Steel Set 314 & $05+71 \mathrm{~m}$ \\
\hline 6 & 975 & $09+75 m$ & 26 & TTF/HD 00+09 & TTF/HD $00+09 \mathrm{~m}$ & 46 & Steel Set 546 & $11+44 \mathrm{~m}$ \\
\hline 7 & Steel Set 554 & $11+55 \mathrm{~m}$ & 27 & Steel Set 1484 & $70+58 \mathrm{~m}$ & 47 & Steel Set 561 & $11+63 \mathrm{~m}$ \\
\hline 8 & 1830 & $18+30 \mathrm{~m}$ & 28 & 7252 & $72+52 \mathrm{~m}$ & 48 & Steel Set 567 & $11+71 \mathrm{~m}$ \\
\hline 9 & 2134 & $21+34 \mathrm{~m}$ & 29 & 7696 & $76+96 \mathrm{~m}$ & 49 & Steel Set 1289 & $60+45 \mathrm{~m}$ \\
\hline 10 & 2770 & $27+70 \mathrm{~m}$ & 30 & SGDFA $01+24$ & SGDFA 01+24 m & 50 & Steel Set 1293 & $60+49 m$ \\
\hline 11 & 2828 & $28+28 \mathrm{~m}$ & 31 & 3061 & $30+61 \mathrm{~m}$ & 51 & Steel Set 1375 & $62+15 \mathrm{~m}$ \\
\hline 12 & 3102 & $31+02 \mathrm{~m}$ & 32 & ECRB 22 & $\mathrm{E} 00+25 \mathrm{~m}$ & 52 & Steel Set 1484 & $70+58 \mathrm{~m}$ \\
\hline 13 & 3401 & $34+01 \mathrm{~m}$ & 33 & ECRB 400 & $E 04+00 \mathrm{~m}$ & 53 & Steel Set 1526 & $71+09 \mathrm{~m}$ \\
\hline 14 & 3737 & $37+37 \mathrm{~m}$ & 34 & ECRB 814 & $\mathrm{E} 08+14 \mathrm{~m}$ & 54 & Steel Set 1542 & $71+29 m$ \\
\hline 15 & 4247 & $42+47 \mathrm{~m}$ & 35 & ECRB 1354 & $\mathrm{E} 13+54 \mathrm{~m}$ & 55 & Steel Set 1626 & $75+21 \mathrm{~m}$ \\
\hline 16 & 4706 & $47+06 \mathrm{~m}$ & 36 & ECRB 1576 & E. 15+76 m & 56 & Steel Set 1652 & $76+77 \mathrm{~m}$ \\
\hline 17 & 5571 & $55+71 \mathrm{~m}$ & 37 & ECRB 1939 & $E$ 19+39 m & 57 & Steel Set 1676 & $77+06 \mathrm{~m}$ \\
\hline 18 & 6055 & $60+55 \mathrm{~m}$ & 38 & ECRB 2178 & E 21+78 m & 58 & Steel Set 1695 & $77+30 \mathrm{~m}$ \\
\hline 19 & 5064 & $50+64 \mathrm{~m}$ & 39 & ECRB 2472 & $E 24+72 m$ & & & \\
\hline 20 & 6200 & $62+00 \mathrm{~m}$ & 40 & ECRB 796 & E $07+96 \mathrm{~m}$ & & & \\
\hline
\end{tabular}

\subsubsection{Measurement Timing}

\subsubsection{Timing of Convergence and Displacement Monitoring}

Current construction monitoring with existing MPBX, SPBX, and convergence stations will continue to be performed on an approximate semiannual frequency. Some of the current station locations are located behind the ECRB bulkheads and may not be accessible on a six-month frequency so data will be collected as accessibility permits. Data analysis of the current stations being measured has shown that the excavated opening at these locations is stable and should not require more frequent data collection.

For future construction monitoring activities, construction effects testing and monitoring will commence as soon as construction is initiated. Displacement or convergence data are planned to be measured on a continuous basis and no schedule of data collection or timing is required.

Access ramps and mains will be the first elements completed and testing and monitoring will begin on those underground components as part of the repository development program. Monitoring of the first emplacement drift will commence as soon as TBM operations are started. Testing and monitoring under this TWP in the first emplacement drift will cease just prior to the start of waste emplacement. 
Mine-by testing will be performed in accordance with the repository and test observation drift excavation schedules. The first monitoring will be performed shortly after the start of excavation of the test observation drift that is planned to extend from the end of the heated drift in Alcove 5.

\subsubsection{Timing of Tunnel Degradation Monitoring}

Tunnel degradation monitoring will follow completion of initial excavation. If there are no unexpected results (measurements exceeding the expected range), observations in emplacement drifts will be conducted on at least a weekly basis for the first three months, monthly for the next three months, and at three-month intervals for the remaining period or until the start of waste emplacement. In the event that any unexpected results are obtained from observation criteria defined in Section 2.2.1.3 at any time prior to the completion of this test activity (i.e., prior to the start of waste emplacement), the observation schedule will revert to the initial schedule of at least weekly observations. For existing excavated openings, monitoring will continue on an approximate semiannual basis.

\subsubsection{Test Implementation and Work Control Documents}

A new FWP containing implementation and work control details will be prepared in accordance with PA-PRO-0308 by the TCO for performance of the current performance confirmation test activities described in this TWP. This new FWP will supersede the existing FWP-ESF-96-002, Construction Monitoring in the ESF. The TCO also has prepared Test Work Authorizations (in accordance with PA-PRO-0308) for control of conduct of the field test activities. FWPs are typically not required for laboratory testing activities as laboratory tests do not impact the site and are controlled under the testing laboratory facility Quality Assurance, safety and health, and chemical hygiene plans and technical procedures. Technical procedures will be used for actual field installation and measurement activities. Appendix B lists applicable technical procedures used to perform construction effects testing and monitoring activities. Additional procedures will be developed, as needed, for field activities.

\subsection{DATA ACQUISITION, ANALYSIS, AND REPORTING OF RESULTS}

\subsubsection{Data Acquisition}

The electronic instrumentation identified in this TWP will most likely in the future be connected to a permanent digital control and management information system as described in Digital Control and Management Information System Description Document (BSC 2005 [DIRS 173622]) to collect the measured electronic data. Currently, however, data collection utilizes a portable data logger that contains a Campbell Scientific CR10 measurement and control module (or equivalent), or is collected manually using a Geokon GK403 Readout Box (or equivalent). The Data Collection System and the portable data logger use Campbell Scientific PC208 software to display and download the data. Data archived by the portable data loggers will be periodically downloaded by field technicians. All data handling is performed per requirements given in IT-PRO-0009. Once downloaded, the data are compiled via Microsoft Excel spreadsheets and transmitted to the TDMS per requirements given in AP-SIII.3Q, Submittal and Incorporation of Data to the Technical Data Management System. As 
technological advances are made in equipment and associated methods updated, the plan will be revised to incorporate these changes to improve efficiency and data quality.

In cases where measurements produce apparent erroneous data, the measurement shall be repeated immediately, if necessary, to confirm values obtained. This might occur in data that have been collected manually by field technicians (e.g., convergence tape measurements). Field technicians will check equipment and hardware, as described in technical procedures, to identify areas where data collection errors might have occurred. The PI will determine if the data are acceptable, in cases of apparent erroneous data collection, after inspection of the data collection hardware and monitoring equipment.

The first and most likely source of an unexpected condition is human error when taking a manual reading or entering data into data forms or into databases. To minimize human error, the following should be implemented:

- Reference previously recorded data when taking a manual reading

- Have the data recorder read the data entry to the data reader

- Review database entries

- Develop an electronic data collection system.

\subsubsection{Data Analysis}

The primary responsibility for general data analysis requirements rests with the PI. The following will routinely be performed:

- Confirmation that applicable data acquisition procedures have been followed

- Confirmation that calibration of the relevant instrumentation system(s) is in accordance with applicable procedures

- Review of parameter data against the current parameter baseline, expected range and/or condition limits, as discussed in Sections 2.3.2.1 and 2.3.2.2

- Review of parameter data for trends

- For data within the current baseline or the expected range, or both, and for which there are no apparent trends, approval of the data for submittal to the TDMS in accordance with procedures

- For parameter data outside the expected range and/or with apparent developing trends, review of the data in accordance with Sections 2.3.2.1 and 2.3.2.2. 


\subsubsection{Rock Convergence}

The confirmation of convergence data will be a two-step process as a part of this TWP. The first step will use tunnel deformation data collected from MPBX or similar deformation instruments at monitoring locations. These measurements will be the primary data collected under this TWP. Data will be adjusted (discussed below) to total convergence values, and these values will then be used to determine if predicted deformations have been exceeded. Secondly, an evaluation will be initiated of any values exceeding established range limits, including supplemental testing and monitoring, as required.

For convergence monitoring stations in the ESF, the lag time between the first convergence readings and the excavation date ranges from several days to several months, indicating that the initial convergence at a monitoring station (which occurs both prior to excavation and immediately after excavation) has not been measured. This unmeasured initial convergence represents a significant part of the total convergence and has been determined to be $75 \%$ of the total convergence value (BSC 2004 [DIRS 168178], p. 29). Thus, the measured convergence only represents $25 \%$ of the total convergence. Based on this, values of measured vertical roof deformation will first be multiplied by 2 to obtain a convergence value (as convergence is represented by roof and invert deformation, which are assumed equal in magnitude), and then multiplied by 4 to obtain the estimated value of total convergence that will be compared to values given in Table 1-1. Initial convergence data for lithophysal rock will be determined during future mine-by tests and may be used to refine these factors in the future.

If the expected range of convergence is exceeded in any rock category for either lithophysal or nonlithophysal rock in accordance with Table 1-1, an internal evaluation will be conducted by the Performance Confirmation organization to collect further information or data to substantiate monitoring results. This evaluation will determine whether the condition requires reporting to the NRC, based on whether it is determined that the out-of-bounds condition identified is representing a localized anomaly in the rock or it challenges the assumptions made, or parameter values used, in the design supporting LA. If the latter is determined, reporting to the NRC through the DOE will be required. Because only Category 1 rock (poorest quality) was used in the supporting design analyses, values of convergence for rock Categories 2 through 5 that are within the Category 1 expected range values given in Table 1-1 will be considered within the expected range for design.

\subsubsection{Tunnel Degradation}

Emplacement drift degradation will be evaluated based on observations performed as part of this TWP. Areas inside emplacement drifts indicating rockfall and raveling, or other areas identified through subsurface mapping, may be instrumented as approved by the Performance Confirmation organization. Areas of continuous raveling rock or keyblock failure will be reported as a condition exceeding those assumed for the preclosure tunnel condition described in Ground Control for Emplacement Drifts for LA (BSC 2004 [DIRS 170292]). The analysis has determined that the largest rockfalls occurring in emplacement drifts are predicted to be up to $1.3 \mathrm{~m}^{3}$ per event. This value is used as a basis for the expected range and condition limit for rockfall that is allowable in the emplacement drifts without requiring further evaluation. The 
upper value of this range has also been set as the condition limit, and thus exceeding of this value will require internal and external reporting.

For lithophysal rock units, an area that exhibits smaller persistent rockfall (raveling) exceeding $1.3 \mathrm{~m}^{3}$ will require internal reporting of the exceeded range. Although the value of $1.3 \mathrm{~m}^{3}$ was used in design analysis for nonlithophysal rock, this plan has also set this value as a condition limit for lithophysal rock in identified areas of persistent raveling. An area exceeding this expected range might require further ground support or isolation as determined from engineering evaluation performed following exceeding of the limit. This evaluation will determine whether the condition requires reporting to the $\mathrm{NRC}$, based on whether it is determined that the out-of-bounds condition identified represents a very localized anomaly in the rock, or whether it is indicative of an error in characterization of rock unit input values used in models supporting LA. This is because geotechnical parameter input values used in the design of the subsurface openings are representative of the anticipated rock mass properties in general and do not necessarily take into account localized areas of weaker rock material associated with faults or other possible weak areas that are not anticipated by design, but nevertheless, could still be encountered. If the out-of-bound condition is not localized then reporting to the NRC, through the DOE, will be required.

\subsubsection{Data Submittal and Reporting}

Data submittal and reporting will be as follows:

- All reduced data will be submitted to the TDMS.

- Data and evaluation of data performed under this TWP will be compiled and included in a regular annual report prepared by the Performance Confirmation organization. This report, following approval by YMP management and the DOE, will serve as the basis for required reporting to the NRC.

\subsection{PROVISIONS FOR UNEXPECTED RESULTS, CONDITIONS, AND | OUT-OF-RANGE EVENTS}

\subsubsection{General Provisions}

As predicting long-term performance for the repository at Yucca Mountain is complex and of | long duration, some deviations from expectations will probably occur. Documentation, tracking, and management of deviations potentially significant and related to confirmation, as described in this TWP, are the responsibility of the Performance Confirmation Manager and start with recording the condition in the Corrective Action Program per AP-16.1Q, Condition Reporting and Resolution, followed by evaluations detailed in this TWP (Figure 2-2). This TWP also includes provisions for evaluation and reporting conditions or observations outside condition limits to the DOE and NRC, according to AP-REG-009. 


\subsubsection{Reporting Bases}

This TWP describes each parameter (Tables 1-1 and 1-2), sources of test parameter data, and the test parameter expected ranges with condition limit (rockfall CEM3 only). Through routine reporting, NRC will be kept current on progress of performance confirmation activities and their evaluations. Routine reporting will be accomplished with a protocol of standard reporting format and interval to the NRC in accordance with PA-PRO-0313, Technical Reports, or other I established protocol.

In addition to routine reporting to the DOE, the Performance Confirmation Program will also be subject to formal reporting of conditions that differ from those assumed in analyses supporting LA. The Performance Confirmation Manager will report to the DOE in accordance with AP-REG-009 or equivalent. After an evaluation(s) of the cause of the exceeded limit is performed, an assessment of the potential significance of the deviation and determination of the possible corrective actions will be conducted (Figure 2-2). DOE will notify the NRC of the results of the assessment for those activities where measurements have exceeded the condition limits.

In cases where the evaluation process requires sampling over time, it is possible to observe the time evolution of estimated parameter values and associated uncertainty bands. The time series of reduced data can be analyzed to determine whether there is evidence of a trend that, if it were to continue, would eventually challenge assumptions supporting the LA and/or adversely impact repository operations. If such a trend is identified, action will be initiated by the Performance Confirmation Manager to evaluate the possible consequences and determine the necessity for internal reporting. . Figure 1-3 illustrates typical trend curves. If determined necessary by the Performance Confirmation Manager, this evaluation may be performed by an integrated group of individuals who address both technical and interface issues. Three categories of data will be collected under the scope of this TWP: rock displacement, tunnel degradation, and necessary geomechanical rock properties. Evaluation criteria must be used to determine in each of these categories whether or not the data are within the expected range and condition limit. Following collection, the PI or PI designee will evaluate data against the expected ranges or criteria given for each of the data categories. In addition to reporting exceedance of established parameter ranges, the PI will notify subsurface engineering and the safety department of any trends of subsurface opening convergence that indicate an unstable condition may exist, per Figure 1-3. This is required since a potential for personnel exposure to a hazardous underground condition may exist if the opening is determined unstable by the geotechnical engineering staff. Required reporting, as shown in Figure 2-2 and discussed here, will occur following this notification. 


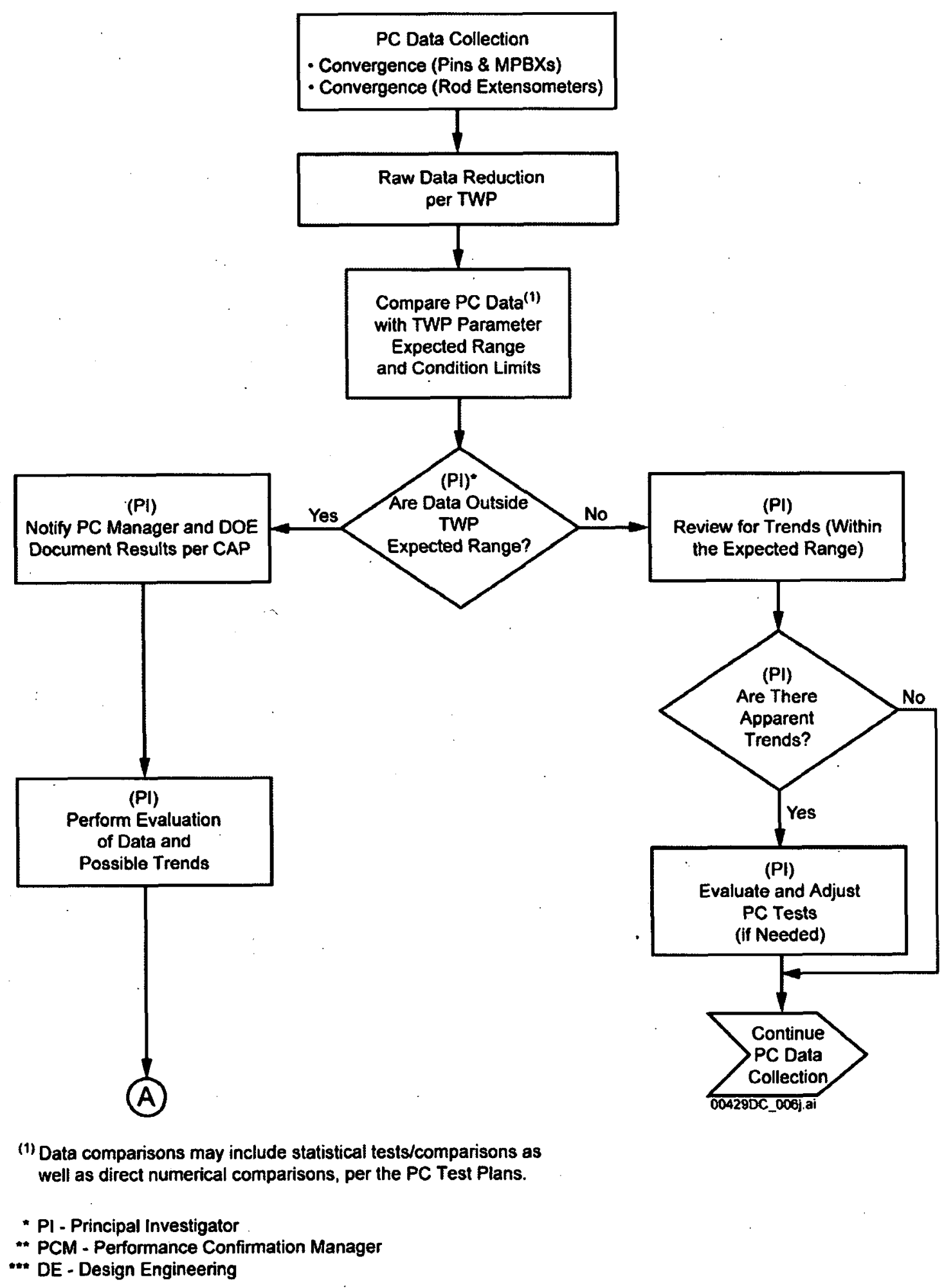

Figure 2-2. Data Review and Reporting 


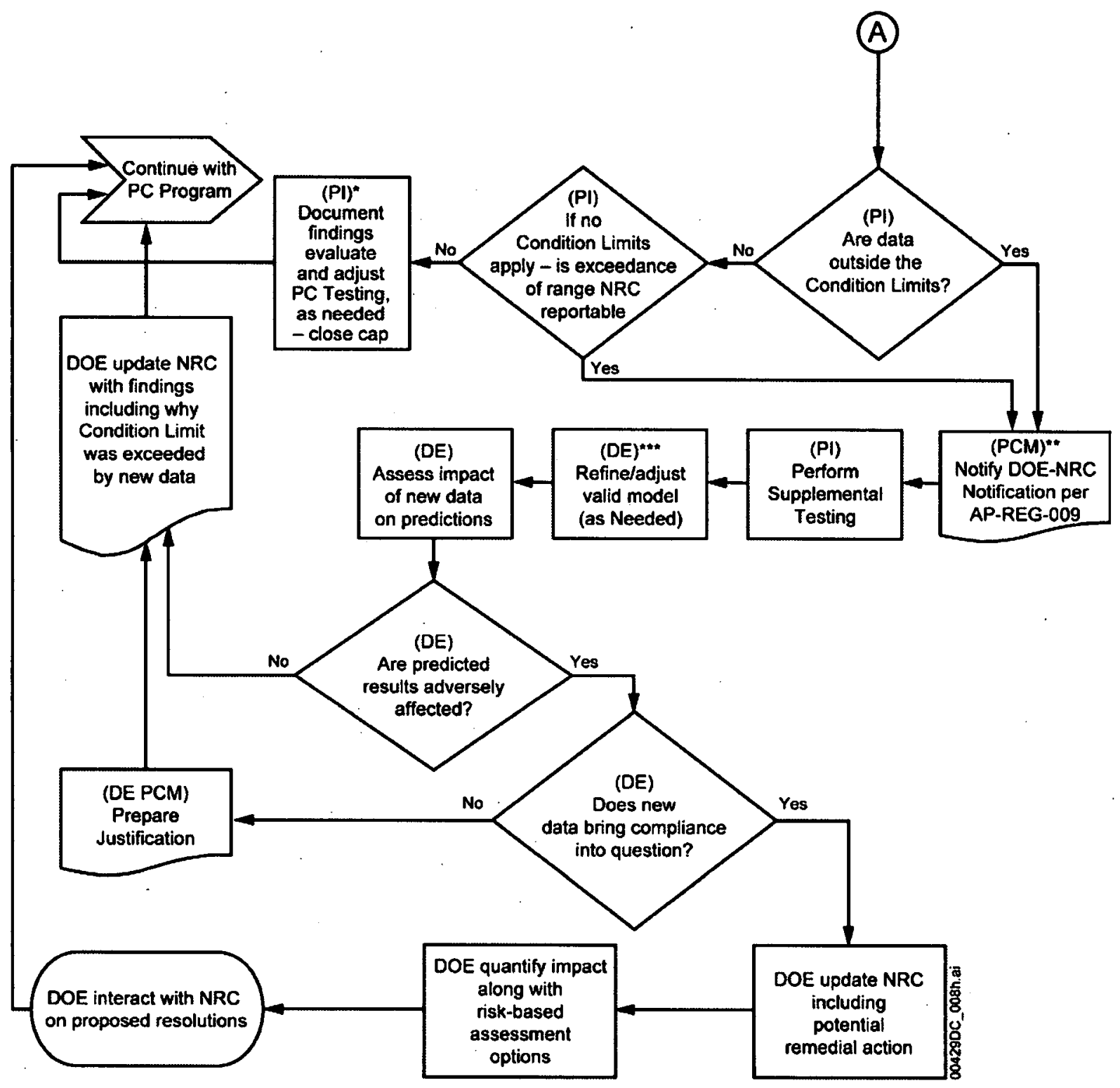

- PI - Principal Investigator

** PCM - Performance Confirmation Manager

** DE - Design Engineering

Figure 2-2. Data Review and Reporting (Continued) 


\subsection{FEATURES, EVENTS, AND PROCESSES}

As noted in the introduction, the Upper Natural Barrier System, Engineered Barrier System, and Lower Natural Barrier System have been evaluated as to their performance in terms of associated FEPs. The characteristics of each FEP in terms of effects on barrier performance have been identified for performance evaluation purposes. FEPs with significant impact on performance have been categorized as Important to Barrier Capability. No FEPs have been identified within the scope of this planned activity with significant impact on barrier performance, and thus activities within this TWP are not considered important to waste isolation.

\section{INDUSTRY STANDARDS, FEDERAL REGULATIONS, DOE ORDERS, AND REQUIREMENTS}

Requirements for this document are derived from pertinent federal regulations, as discussed in Section 1.1. Technical test requirements for this plan are provided by Performance Confirmation Plan (BSC 2004 [DIRS 172452]). Orders and standards have not been determined as requirements sources for this TWP.

\subsection{INDUSTRY STANDARDS}

Industry standards will generally be applied to specific parameter test methods and are identified in the specific test procedures or in relevant FWPs, or both, as required. For laboratory tests (e.g., rock properties testing of samples), the standards will be identified in relevant laboratory procedures.

\subsection{ACCEPTANCE/COMPLETION CRITERIA}

Construction and monitoring data collection will continue through the preclosure period or until it is determined no longer required. The monitoring of emplacement drifts will continue until the end of the construction period and testing and monitoring of tunnel mains will be completed at the end of the preclosure period. Acceptance criteria for data collected will be based on the requirements established in Section 2.3.1.

\subsection{SOURCES OF ERROR OR UNCERTAINTY}

Sources of error or uncertainty related to the data collection of the test and monitoring activities associated with this TWP will be identified and mitigated as per technical procedures used for field test implementation and as discussed in Section 2.3.1.

\section{IMPLEMENTING DOCUMENTS}

A listing of generally applicable implementing procedures is provided in Appendix B. Additional implementing documents are provided in FWP-ESF-96-002 and testing laboratory procedures. The Performance Confirmation, TCO, or other laboratory departments will develop future test and monitoring activities technical procedures, as required. 


\section{FIELD AND LABORATORY SYSTEMS AND EQUIPMENT}

\subsection{MAJOR SYSTEMS AND EQUIPMENT}

Equipment used for monitoring performed in this TWP is described in Section 2.2.

\subsection{CALIBRATION REQUIREMENTS}

Calibration will be performed on equipment in accordance with the requirements provided in Section 2.2, technical procedures, and in accordance with LP-12.1Q-BSC and QA-PRO-1071, Acceptance of Items \& Services.

\section{RECORDS}

Records of testing and monitoring work performed under this TWP will be prepared and submitted in accordance with AP-17.1Q.

\section{QUALITY VERIFICATIONS}

The Performance Confirmation Program, including this construction effects testing and monitoring activity, will be conducted in compliance with 10 CFR Part 63, Subpart F, including 10 CFR 63.142 [DIRS 173273]. Additional quality verifications will be conducted as prescribed by Quality Management Directive and referenced documents (e.g., DOE 2006 [DIRS 176927]). Any special hold points will be detailed in the FWP for each test parameter. These will include the requirements associated with internal reviews and NRC reporting and reviews as described in Section 2.4 .

\section{PREREQUISITES, SPECIAL CONTROLS, ENVIRONMENTAL CONDITIONS, PROCESSES, OR SKILLS}

\subsection{QARD REQUIREMENTS}

Work performed under this TWP will be performed in accordance with the QARD (DOE 2006 [DIRS 176927]).

\subsection{PREREQUISITES}

Before commencement of activities delineated in this plan, the following will be implemented:

- Approved FWPs

- Approved test work authorization

- Quality-affecting instrument calibration

- Approved field technical procedures for test implementation. 


\subsection{CONTROL OF ELECTRONIC MANAGEMENT OF INFORMATION}

Electronic management of information is controlled by applicable procedures (Appendix B) and detailed in FWP-ESF-96-001, or testing laboratory procedure, or both. An evaluation has been performed in development of this plan per LP-2.29Q-BSC.

\subsection{ENVIRONMENTAL CONTROLS}

Environmental controls may be required for construction effects testing and monitoring and will be detailed in FWP-ESF-96-002.

\subsection{SPECIAL TRAINING/PERSONNEL QUALIFICATIONS}

Special training and personnel qualifications are detailed in FWP-ESF-96-002 or the testing procedures, or both, as required.

\section{SOFTWARE}

Campbell Scientific PC208W, Microsoft Access ${ }^{\mathrm{TM}}$, and Microsoft Excel ${ }^{\mathrm{TM}}$ are required to support the current activities described by this plan. Campbell Scientific PC208W has been qualified under IT-PRO-0011 and the Campbell Scientific PC208W Software Management Report (STN: 10739-3.2-00). PC208W is a utility used to configure and to download data from the Campbell Scientific CR10 dataloggers. Access ${ }^{\mathrm{TM}}$ and Excel ${ }^{\mathrm{TM}}$ spreadsheets are utilized consistent with IT-PRO-0011. Acquired and developed electronic data shall be handled according to IT-PRO-0009.

\section{ORGANIZATIONAL INTERFACES}

Organizational interfaces are identified in Section 1.4.

\section{PROCUREMENT}

Calibration services will be performed under subcontracted service. Required procurement activities will be conducted in accordance with applicable BSC procedures (Appendix B). USGS personnel will use applicable USGS procedures, as needed.

\section{REFERENCES}

\subsection{DOCUMENTS CITED}

The following references are cited in this TWP (exclusive of those which are implementing procedures). Implementing procedures are listed in Appendix B.

170210 BSC (Bechtel SAIC Company) 2003. Test Plan for: Construction Monitoring Equipment Installation and Data Collection. SITP-03-EBS-002 REV 00. Las Vegas, Nevada: Bechtel SAIC Company. ACC: DOC.20030626.0005. 
170292 BSC 2004. Ground Control for Emplacement Drifts for LA. 800-K0C-SSE000100-000-00A. Las Vegas, Nevada: Bechtel SAIC Company.

ACC: ENG.20040712.0019; ENG.20050816.0015.

168178 BSC 2004. Ground Control for Non-Emplacement Drifts for LA.

800-KMC-SSD0-00700-000-00A. Las Vegas, Nevada: Bechtel SAIC Company. ACC: ENG.20040302.0022; ENG.20050816.0022.

172452 BSC 2004. Performance Confirmation Plan. TDR-PCS-SE-000001 REV 05. Las Vegas, Nevada: Bechtel SAIC Company. ACC: DOC.20041122.0002.

173622 BSC 2005. Digital Control and Management Information System Description Document. 000-3YD-JD00-00100-000-006. Las Vegas, Nevada: Bechtel SAIC Company. ACC: ENG.20050620.0003.

176927 DOE (U.S. Department of Energy) 2006. Quality Assurance Requirements and Description. DOE/RW-0333P, Rev. 17. Washington, D.C.: U.S. Department of Energy, Office of Civilian Radioactive Waste Management.

ACC: DOC.20060504.0008.

163274 NRC (U.S. Nuclear Regulatory Commission) 2003. Yucca Mountain Review Plan, Final Report. NUREG-1804, Rev. 2. Washington, D.C.: U.S. Nuclear Regulatory Commission, Office of Nuclear Material Safety and Safeguards. TIC: 254568 .

166219 Snell, R.D.; Beesley, J.F.; Blink, J.A.; Duguid, J.O.; Jenni, K.E.; Lin, W.; Monib, A.M.; Nieman, T.L.; and Hommel, S. 2003. Performance Confirmation Plan. TDR-PCS-SE-000001 REV 02 ICN 02. Las Vegas, Nevada: Bechtel SAIC Company. ACC: DOC.20031124.0003.

\subsection{CODES, STANDARDS, REGULATIONS}

173273 10 CFR 63. 2005 Energy: Disposal of High-Level Radioactive Wastes in a Geologic Repository at Yucca Mountain, Nevada. ACC: MOL.20050405.0118.

\subsection{DATA, LISTED BY DATA TRACKING NUMBER}

SN0405F3312393.015. Tunnel Convergence and MPBX Data (with Results from $7 / 3 / 1999$ through $2 / 5 / 2004$ ) 


\section{INTENTIONALLY LEFT BLANK}


APPENDIX A

GLOSSARY 


\section{APPENDIX A - GLOSSARY}

Accuracy-The degree to which a calculation, measurement, or set of measurements agree with a true value or an accepted reference value.

Barrier-Any material, structure, or feature that, for a period to be determined by NRC, prevents or substantially reduces the rate of movement of water or radionuclides from the Yucca Mountain repository to the accessible environment, or prevents the release or substantially reduces the release rate of radionuclides from the waste. For example, a barrier may be a geologic feature, an engineered structure, a canister, a waste form with physical and chemical characteristics that significantly decrease the mobility of radionuclides, or a material placed over and around the waste, provided that the material substantially delays movement of water or radionuclides.

Baseline-A set of information (developed from site characterization data, modeling assumptions or results, design bases and specifications, other relevant analogue or technical information) and analysis of that information on those parameters selected to be monitored, tested, evaluated, or observed during the Performance Confirmation Program. The baseline is the standard to which comparisons are made, by parameter, to evaluate performance confirmation data. For purposes of the Performance Confirmation Plan, the baseline includes expected range, condition limits, and trend indicators (see Baseline condition).

Baseline condition-A set of critical observations or data used for comparison or a control. When hypothesis testing is applied to performance confirmation decisions, data are used to choose between a presumed baseline condition and an alternative condition. Baseline conditions are also referred to as the baseline for statistical comparisons. Deviations from the baseline do not necessarily impact performance, only where the trend is unexpected or they exceed a predetermined decision point (action level) based on performance assessment sensitivity analysis.

Confirmation, or to confirm-In the context of the Performance Confirmation Program, means to evaluate the adequacy of assumptions, data, and analyses that led to the findings that permitted construction of the repository and subsequent emplacement of the wastes.

Condition limit-The discrete value(s) or trend(s) outside (upper or lower) the expected range that results in more detailed evaluation and potentially additional sampling (including adversely developing trends). The condition limit is defined during the planning phase of a data collection activity (based on that parameter's importance to performance); it is not calculated from the sampling data. Condition limits for parameters will be discussed in the performance confirmation TWP for that activity.

Design bases-Information that identifies the specific functions to be performed by items and the specific values or ranges of values chosen for controlling parameters as reference bounds for design.

Disposal-The emplacement of radioactive waste in a geologic repository with the intent of leaving it there permanently. 
Dose - The total effective dose equivalent means, for purposes of assessing doses to workers, the sum of the deep-dose equivalent (for external exposures) and the committed effective dose equivalent (for internal exposures). For purposes of assessing doses to members of the public, total effective dose equivalent means the sum of the effective dose equivalent (for external exposures) and the committed effective dose equivalent (for internal exposures).

Drift-The near-horizontal underground excavations from the shaft(s) or ramp(s) to the other excavations such as alcoves and rooms. The term includes excavations for emplacement (emplacement drifts) and access (access mains).

Drip shield-A component of the Engineered Barrier System. The drip shield is above the waste package and is designed to (1) prevent seepage from dripping directly onto the surface of the waste package, and (2) to mitigate the effects of rockfall.

Emplacement-The placement and positioning of spent nuclear fuel or high-level radioactive fuel (i.e., waste packages) in prepared locations within excavations of a geologic repository.

Emplacement drift-A drift in which waste packages are placed.

Engineered Barrier System-The waste packages, including engineered components and systems other than the waste package (e.g., drip shields), and the underground facility.

Expected range-The range of values for an input parameter, including factors to account for variability, that is most likely expected based on historical test data, material standards, or calculated values.

Experiment-A test under controlled conditions.

Exploratory Studies Facility-An underground facility at Yucca Mountain used for performing site characterization studies. The facility includes a 7.9-km (4.9-mi) main loop (tunnel), the 2.8-km (1.7-mi) Enhanced Characterization of the Repository Block Cross-Drift, and a number of alcoves used for site characterization tests such as the Drift Scale Test.

Feature-A natural barrier, structure, characteristic, process, or condition that functions to prevent or reduce the movement of water or prevent the release or substantially reduce the release rate of radionuclides.

Geologic repository-A system that is intended to be used for, or may be used for, the disposal of radioactive waste in excavated geologic media. A geologic repository includes the geologic repository operations area, and the portion of the geologic setting that provides isolation of the radioactive waste.

Geologic repository operations area-A high-level radioactive waste facility that is part of a geologic repository, including both surface and subsurface areas, where waste handling activities are conducted.

Geologic setting-The geologic, hydrologic, and geochemical systems of the region in which a geologic repository is or may be located. 
Host rock-(1) The rock unit in which the potential repository would be located. For a repository at Yucca Mountain, the host rock would be the middle portion of the Topopah Spring Tuff of the Paintbrush Group. (2) The geologic medium in which the waste is emplaced.

in situ - In its natural position or place. The phrase distinguishes between tests or experiments conducted in the field (e.g., in an underground excavation, in-place) from tests and experiments conducted in a laboratory.

Lithophysal-Pertaining to welded tuff units with lithophysae, small, bubble-like holes in the rock caused by volcanic gases trapped in the rock matrix as the ash-flow tuff cooled, often having concentric shells of finely crystalline alkali feldspar, quartz, and other materials that were formed by the entrapped gases that later escaped.

Model-A representation of a system, process, or phenomenon, along with hypotheses required to describe the process or system or to explain the phenomenon, often mathematically. Model development typically progresses from conceptual models to mathematical models.

Monitoring-To keep track of systematically with a view to collecting information and to analyze or sample, especially on a regular or ongoing basis. In performance confirmation, monitoring is generally long-term observation or sampling for a parameter or set of parameters.

Parameter-Scientific data, performance assessment data, or engineering technical information that represent physical or chemical properties, consisting of an assigned variable name and generally represented by a value or range of values. Select parameters that potentially are subject to varied interpretation and selection of multiple values, and subject to multiple use for various technical products within the YMP, reside in the TDMS (see sample).

Performance assessment-An analysis that: (1) identifies the features, events, processes (except human intrusion), and sequences of events and processes (except human intrusion) that might affect the Yucca Mountain disposal system and their probabilities of occurring during 10,000 years after disposal; (2) examines the effects of those features, events, processes, and sequences of events and processes upon the performance of the Yucca Mountain disposal system; and (3) estimates the annual dose incurred by the reasonably maximally exposed individual, including the associated uncertainties, as a result of releases caused by all significant features, events, processes, and sequences of events and processes, weighted by their probability of occurrence.

Performance confirmation-The program of tests, experiments, and analyses conducted to evaluate the accuracy and adequacy of the information used to demonstrate compliance with the postclosure performance objectives in Subpart E of 10 CFR Part 63 [DIRS 173273].

Permanent closure-Final backfilling of the underground facility, if appropriate, and the sealing of shafts, ramps, and boreholes.

Precision-A measure of mutual agreement among individual measurements of the same property. 
Process model-A mathematical model that represents an event, phenomenon, process, component, etc., or series of events, phenomena, processes, or components, etc. A process model may undergo an ábstraction for incorporation into a system model.

Retrieval-The act of permanently removing radioactive waste from the underground location at which the waste had previously been emplaced for disposal.

Risk-informed, performance-based-An approach to decision-making whereby risk insights are considered together with other factors to establish requirements that better focus attention on design, operation, and performance issues commensurate with their importance to public heath and safety.

Sample (statistical) - In statistics, a set of data from the population.

Seepage-The flow of the groundwater in fractures or pore spaces of permeable rock to an open space in the rock; the percolation flux that enters an underground opening.

Seismic - Pertaining to, characteristic of, or produced by earthquakes or earth vibrations.

Seismic event-An earthquake.

Significance-An effect is said to be significant if the value of the statistic used to test it lies outside defined limits, that is to say, if the hypothesis that the effect is not present is rejected. A test of significance is one that, by use of a test statistic, purports to provide a test of the hypothesis that the effect is absent. By extension, the critical values of the statistics are themselves called significant.

Site-That area surrounding the geologic repository operations area for which DOE exercises authority over its use in accordance with the provisions of 10 CFR Part 63 [DIRS 173273].

Site characterization - The program of exploration and research, both in the laboratory and in the field, that is undertaken to establish the geologic conditions and the ranges of parameters of a particular site that are relevant to the implementing documents.

Total system performance assessment-A risk assessment that quantitatively estimates how the proposed Yucca Mountain repository system performs in the future under the influence of specific features, events, and processes, incorporating uncertainty in the models and data. Its purposes are: (1) provide the basis for predicting system behavior and for testing that behavior against safety measures in the form of regulatory standards, (2) provide the results of total system performance assessment analyses and sensitivity studies, (3) provide guidance to site characterization and repository design activities, and (4) help prioritize testing and selection of the most effective design options.

Trend-A long-term movement in an ordered series, which may be regarded, together with the oscillation and random component, as generating the observed values. 
Tuff-Igneous rock formed from compacted volcanic fragments created from pyroclastic (explosively ejected) flows with particles generally smaller than $4 \mathrm{~mm}$ in diameter; the most abundant type of rock at the Yucca Mountain site.

Uncertainty-A quantitative or qualitative measure of how well a mathematical model represents a system, process, or phenomenon; or the interval above and below the measurement, parameter, or result that contains the true value. There are two types of uncertainty: (1) Stochastic (or aleatory) uncertainty caused by the random variability in a process or phenomenon, (2) State-of-knowledge (or epistemic) uncertainty, which results from a lack of complete information about physical phenomena. State-of-knowledge uncertainty is further divided into: (i) Parameter uncertainty, which results from imperfect knowledge about the inputs to analytical models, (ii) Model uncertainty, which is caused by imperfect models of physical systems, resulting from simplifying assumptions or an incomplete identification of the system modeled, and (iii) Completeness uncertainty, which refers to the uncertainty as to whether the important physical phenomena, relationships (coupling), and events have been considered.

Underground facility - The underground structure, backfill materials, if any, and openings that penetrate the underground structure (e.g., ramps, shafts, and boreholes, including their seals).

Variability-Refers to the observed difference attributed to heterogeneity or diversity in a population. Sources of variability are the results of natural random processes and stem from the differences among the elements of a population. Variability is not usually reducible by further measurement but can be better estimated by increased sampling based on the understood or assumed distribution in the parameter's physical attributes.

Variance-In performance confirmation, a difference between what is expected or predicted and what actually occurs. In statistics, the total variation displayed by a set of observations, as measured by the sums of squares of deviations from the mean, may in certain circumstances be separated into components associated with defined sources of variation used as criteria of classification for the observations. Such an analysis is called an analysis of variance, although in the strict sense it is an analysis of sums of squares. Many standard situations can be reduced to the variance analysis form.

Waste form-The radioactive waste materials and any encapsulating matrix.

Waste package-The waste form and any containers, shielding, packing, and other absorbent materials immediately surrounding an individual waste container. 
INTENTIONALLY LEFT BLANK 


\section{APPENDIX B}

APPLICABLE PROCEDURES 
INTENTIONALLY LEFT BLANK 


\section{APPENDIX B - APPLICABLE FWPs AND PROCEDURES}

\section{B.1. TEST PLANS}

LP-2.29Q-BSC, Planning for Science Activities.

\section{B.2. TEST CONTROLS}

FWP-ESF-96-001, Field Test Data Collection Systems

FWP-ESF-96-002, Construction Monitoring in the ESF

IT-PRO-0009, Control of the Electronic Management of Information

IT-PRO-001 1, Software Management

IT-PRO-0013, Software Independent Verification and Validation

PA-PRO-0313, Technical Reports

LP-SIII.11Q-BSC, Scientific Notebooks

PA-PRO-0308, Testing Work Implementation and Control

PA-PRO-0601, Document Review.

\section{B.3. RECORD CONTROLS}

AP-17.1Q, Records Management

AP-SIII.3Q, Submittal and Incorporation of Data to the Technical Data Management System.

\section{B.4. EQUIPMENT/INSTRUMENT CALIBRATION RECORDS}

QA-PRO-1071, Acceptance of Items and Services

LP-12.1Q-BSC, Control of Measuring and Test Equipment.

\section{B.5. NONCONFORMANCES AND CORRECTIVE ACTIONS}

AP-16.1Q, Condition Reporting and Resolution

AP-REG-009, Reportable Geologic Condition.

\section{B.6. PROCUREMENT}

EG-PRO-3DP-G06B-00002, Subcontracts

EG-PRO-3DP-G04B-00057, Technical Service Contracts. 
EG-PRO-3DP-G06B-00001, Material Requisitions

\section{B.7 ANNUAL AND INTERIM REPORTING}

PA-PRO-0313, Technical Reports. 